Estudios Constitucionales, Año 10, No 2, 2012, pp. 455 - 510.

ISSN 0718-0195

Centro de Estudios Constitucionales de Chile Universidad de Talca

"Un constitucionalismo inocuo"

Enzo Solari

\title{
UN CONSTITUCIONALISMO INOCUO
}

\author{
A HARMLESS CONSTITUTIONALISM ${ }^{1}$
}

ENZO SOLARI

Pontificia Universidad Católica de Valparaíso

esolaria@gmail.com

RESUMEN: la ingenuidad e inocuidad que todavía exhibe el constitucionalismo chileno y el propio Tribunal Constitucional, cuando se los pone en comparación con otras dogmáticas y otros tribunales que sí han identificado y discutido el inevitable conflicto que plantea el principio democrático al mecanismo del control judicial de constitucionalidad, parece declinar últimamente aunque sin desaparecer del todo.

ABSTRACT: compared to other constitutional theories and judicial systems that have identified and contend with the inevitable conflict posed by the democratic principle as applied to the constitutionality review process by the judiciary, the ingenuousness and innocuousness still exhibited by the constitutional theory in Chile and its very Constitutional Court seem to fade away momentarily, though without disappearing completely.

PALABRAS CLAVE: constitucionalismo, democracia, control judicial.

KEY WORDS: constitutionalism, democracy, judicial review.

\section{INTRODUCCIÓN}

1. En el considerando $70^{\circ}$ de la sentencia de 18 de abril de 2008, el Tribunal Constitucional de Chile (=TC) ha sostenido que su decisión debe ser acatada por los órganos del Estado y en general por toda persona, institución o grupo, "[...] porque ha ejercido la tarea que el propio Constituyente le ha confiado de velar por la supremacía, sustantiva y formal, de la Carta Fundamental"2. Antes, en el considerando $9^{\circ}$ de su sentencia de 11 de enero de 2007, el TC había dicho que no legisla ni administra, y que por ello mismo su competencia excluye un pronunciamiento acerca del mérito o bondad del acto legislativo o administrativo impugnado o controlado. El TC, agregaba, solamente resuelve si tales actos se ajustan a o no a la constitución chilena, vale decir, si vulneran o no los límites constitucionalmente fijados, pero no debe inmiscuirse en la

${ }^{1}$ El artículo fue recibido el 23 de mayo de 2012 y fue aprobado el 10 de octubre de 2012.

2 TC, Rol No 740, de 8 de abril de 2008, p. 142. 
esencia del ejercicio de la función pública del Congreso, del Presidente o de los demás Tribunales de Justicia. Sin embargo de lo cual, agrega ya menos tímidamente, al resolver

"[...] el Tribunal sustituye la voluntad de los sujetos involucrados en el conflicto, haciendo prevalecer su voluntad por sobre la del órgano controlado. En otros términos, el Tribunal Constitucional sustituye la voluntad de los parlamentarios o la del Presidente de la República. Lo expresado demuestra la gravedad de la decisión y la consiguiente necesidad de contar con reglas claras y precisas de competencia" 3 .

Por lo demás, agregan algunos ministros del TC en el considerando $15^{\circ} \mathrm{de}$ un voto de julio de 2012,

“[...] en nuestro régimen positivo, que parte del principio de control jurídico y no de la inmunidad de los actos estatales, la 'presunción de constitucionalidad de las leyes' no puede aceptarse si no se deduce de ciertos antecedentes o circunstancias conocidas. Menos cuando ella viene siendo desusada hasta en su mismo país de origen, en tanto no venga acompañada con otros elementos de juicio, según autorizada y reciente doctrina. Porque sustentar una tal suposición respecto de todas las leyes, sobre la sola base de provenir de los competentes órganos democráticos, esto es únicamente por incumbir a decisiones legislativas mayoritarias, importaría amagar innecesariamente la supremacía de la Carta Fundamental. Amén de erigirse en una auto restricción infundada para los jueces constitucionales, cuando no se trata más que de examinar el correcto ejercicio jurídico de dicha potestad"4.

\section{¿Plantean estos argumentos algún Problema?}

2. El asunto parece sugerir ciertos límites para las normas jurídicas democráticamente producidas. Más claramente, relevaría algunos asuntos de la regla de la mayoría, añadiendo que los productos de esta regla no tendrían por qué gozar per se de una presunción de constitucionalidad. La democracia liberal, en efecto, supone que las mayorías tienen fronteras. Pero no solamente esto. Para buena parte del constitucionalismo histórico y actual, esas limitaciones

3 TC, Rol No 591, de 1 de septiembre de 2006, p. 32.

${ }^{4}$ TC, Rol No 1961-11, de 10 de julio de 2012, p. 12. La mención de la doctrina se refiere a PosNER (2012). 
son precisamente unos fundamentales derechos por los cuales deben velar algunos jueces. Entonces, claros los deslindes por medio de la garantía de los derechos fundamentales, la democracia sería liberal cuando unos jueces tienen bien determinadas competencias para velar por aquéllos vigilando su constitucionalidad tanto in concreto como a veces in abstracto. ¿Es todo esto natural y obvio? Para contestar, conviene dar un rodeo y generalizar los argumentos del TC.

\section{PRECOMPROMISOS INDIVIDUALES Y CONSTITUCIONES POLÍTICAS}

3. He aquí la misma cuestión pero generalizada: si y cómo las restricciones a que se someten los actos humanos son liberadoras. El esclarecimiento de esta cuestión, claro, dependerá del ángulo con que se la enfrente. Desde un punto de vista individual, las acciones son sistemas de actos ${ }^{5}$ en los que se advierten rasgos (o haces de rasgos) como la voluntariedad y la intencionalidad. Dejando al margen las disputas sobre la descripción y sobre la existencia incluso de estos rasgos, cabría decir en este sentido que las acciones, integradas como están por actos emocionales y desiderativos y por los variados efectos prácticos del transcurso temporal, exhiben fenómenos característicos: la debilidad de la voluntad o incontinencia, la intemperancia o falta de moderación, etc. De hecho, tales fenómenos son las razones o motivos de que se empleen precompromisos, esto es, mecanismos autorrestrictivos que pueden favorecer el control de las acciones futuras (en el entendido de que, como decía Mies van der Rohe, less is more). Así, por ej., eliminar opciones, imponer costes, fijar recompensas, crear demoras, cambiar preferencias, invertir en poder de negociación, inducir pasiones o aun la ignorancia. El paradigma de esta autocontención ha sido Ulises, quien, atado al mástil, resistió el canto de las sirenas ${ }^{6}$.

4. Desde el punto de vista social, hay quienes sugieren que existe una analogía entre las acciones individuales y las actuaciones sociales y que, por tanto, estas actuaciones sociales - sistemas de acciones en cuyo transcurso están entreveradas las acciones de los demás- también estarían necesitadas de precompromisos, justamente al mostrarse en ellas fenómenos parangonables a la incontinencia, la inmoderación y otros: mayorías tiránicas, desprecio por

${ }^{5}$ Cuando se habla de actos, acciones y actuaciones, se sigue la nomenclatura de GonZÁlez (1997).

${ }^{6}$ Cf. Elster (2002), p. 20. 
básicos derechos individuales, faltas de respeto e intolerancias de toda laya, etc. Las constituciones - dotadas de supremacía, rigidez y derechos humanos protegidos judicialmente-serían precisamente mecanismos de precompromiso o autorrestricción social análogos a los precompromisos individuales ${ }^{7}$. Otros, en cambio, refutan esta analogía entre individuos y colectividades, pero mantienen la idea según la cual las constituciones pueden ser entendidas como mecanismos institucionalizados de precompromiso (sobre todo mediante el establecimiento de demoras y mayorías calificadas, aunque también con la imposición de costes, la eliminación de opciones y la separación de poderes), los cuales obedecen a razones (como contrarrestar pasiones e intereses, salvar las inconsistencias temporales y fomentar la eficiencia) en último término dirigidas a restringir la regla mayoritaria ${ }^{8}$. Sea de la aceptación de la analogía entre individuos y grupos lo que fuere, el paso desde la tesis descriptiva de la constitución como mecanismo político autorrestrictivo hasta la tesis justificativa de determinados mecanismos de precompromiso constitucional, es solo contingente; unos lo dan ${ }^{9}$, mientras que otros lo evitan ${ }^{10}$.

5. Pues bien: a la luz de estos fenómenos colectivos de autorrestricción, el constitucionalismo es frecuentemente enjuiciado por su contraposición a los ideales democráticos ${ }^{11}$. No parece posible negar esta contraposición diciendo que las constituciones y los derechos son profundamente democráticos, ni resulta fácil defender la productividad que tendría aquélla apelando a la distinción entre momentos de política constitucional altamente desinteresados y desapasionados y momentos de política rutinaria rudamente impulsivos e interesados ${ }^{12}$. Suele decirse, por lo mismo, que bancos centrales y tribunales

\footnotetext{
7 Cf. ELSTER (2002), pp. 112-113, quien cita en esta dirección el Tractatus theologico-politicus de Spinoza, así como obras más recientes de Stockton, Hayek y Sunstein, incluyendo su propia obra anterior: Ulysses and the Sirens. Vid. también, en esta línea, a Holmes (1999), pp. 217-262.

${ }^{8}$ Por todos, cf. Elster (2002), pp. 113-119.

${ }^{9}$ Cf. Páramo (2002), pp. 443-454.

${ }^{10}$ Cf. la posición más reciente de ElsTer (2002), pp. 186-192: la constitución puede ser en efecto un pacto hecho para prevenir el futuro suicidio, pero que corre el riesgo de ser él mismo un pacto suicida.

${ }^{11}$ Para no alargar más estas páginas conviene dar por supuesta la idea de constitucionalismo. Un buen y plural approach conceptual al mismo ofrece la compilación de AleXANDER (1998); gratos esbozos históricos son los de Blanco Valdés (2010a) y (2010b).

${ }^{12}$ Tal como lo han hecho el propio Elster en su obra previa y Ackerman; cf. ELSTER (2002), pp. 190192.
} 
supremos o constitucionales autónomos constituirían precompromisos constitucionales quizá viables, pero no deseables, precisamente por los sacrificios democráticos que acarrean ${ }^{13}$. Y aun cuando no se comparta la indeseabilidad de tales órganos, sí que se impondría admitir que tanto la judicial review que ejecuta in concreto cada juez norteamericano culminando en la Corte Suprema, como el control de constitucionalidad concreto y abstracto concentrado por tribunales constitucionales comunes en Europa y Latinoamérica, constituyen mecanismos de autorrestricción formalmente contramayoritarios y, aún más, democráticamente deficientes, si y porque constituyen dispositivos de craso tutelaje sobre los procesos democráticos ${ }^{14}$. Todo esto, resulta casi obvio, merece ser discutido por la filosofía política y la teoría constitucional.

\section{NEOCONSTITUCIONALISMO ITALIANO}

6. Parejas cuestiones han sido planteadas por el así llamado 'neoconstitucionalismo' en Italia, de donde, si no me equivoco, procede la denominación misma (Pozzolo). Allí, junto a una activa Corte Constitucional, no son pocos los autores italianos que resaltan la importancia (Guastini, Comanducci, Mazaresse, etc.) de la pregunta por la democracia y el constitucionalismo judicial. Entre ellos, Zagrebelsky y Ferrajoli se caracterizan por tratarla de modo histórico y, se diría, altamente esquemático.

7. Contemplando europa continental, Zagrebelsky ha distinguido en su conocida obra entre el Machtstaat absolutista, el Polizeistaat déspota pero ilustrado, el clásico Rechtsstaat de los siglos XIX y XX y el más cercano Estado constitucional de las décadas que siguen a la segunda gran guerra. ¿Qué caracterizaría al Estado constitucional? Dice: cierta declinación de la ley. Y es que de ella se separan por constitucionalización los derechos, la justicia y los principios jurídicos que consagran aquéllos y ésta ${ }^{15}$. Agrega Zagrebelsky que suele lamentarse

\footnotetext{
${ }^{13}$ Cf. Elster (2002), pp. 183-186.

${ }^{14}$ Es lo que piensa R. Dahl, como veremos. Incluso se ha dicho que el control judicial de constitucionalidad podría ser reemplazado satisfactoriamente por jurados constitucionales o tribunales de ciudadanos: cf. GHosh (2010), pp. 327-359.

15 Cf. Zagrebelsky (1995), pp. 21-130. Según Zagrebelsky, "a las concepciones de la interpretación que admiten el recurso a los principios (sean estos de derecho natural o de derecho constitucional) se les objeta generalmente, en nombre de la certeza del derecho, que abrirían el camino al arbitrio de los intérpretes, autorizados a introducir puntos de vista cambiantes en la reconstrucción de las reglas jurídicas y en su aplicación. La certeza del derecho debería descansar, según esta opinión, en un 'corte'
} 
en este derecho por principios del Estado constitucional una fatal tendencia: la de que promovería jueces facciosos, activistas y politizados. Es una objeción, dice Zagrebelsky, asentada en el Estado legislativo de derecho (el Rechtsstaat clásico), cuyo culto a la regla legal suponía una gran uniformidad de sentido y de valor que hoy se ha roto. Pero en el Estado constitucional de derecho, en cambio, domina el pluralismo, y uno que inevitablemente provoca esencial incerteza en la aplicación del derecho ${ }^{16}$. Nada de esto implica, como es obvio, la desaparición de la ley ${ }^{17}$. Hay que proceder con cuidado: la ley pervive en el Estado constitucional, y el legislador democrático es el primer encargado de tomar decisiones dentro del marco de los principios constitucionales ${ }^{18}$. Los jueces en el Estado constitucional, según Zagrebelsky, sólo velan por la constitución, sin ser en caso alguno los dueños del derecho. Claro que el activismo judicial es un riesgo patente en el Estado constitucional, pero tal cosa sólo debiese ser conjurada con jueces que mantengan el equilibrio (un difícil equilibrio, hay que admitirlo $)^{19}$.

8. Ferrajoli, a su turno, asegura que los derechos fundamentales-leyes del más débil, dice, que ciñen el ámbito de lo indecidible-son límites y vínculos impuestos tanto a los poderes públicos (vale decir, a las mayorías que gobiernan) como a los poderes privados (es decir, a propietarios y administradores que gozan de posiciones determinantes en el mercado ${ }^{20}$. En este sentido, el Estado constitucional de derecho es como la cara sustancial de la democracia moderna. Para la producción legislativa, en efecto, las normas constitucionales sustantivas -que descansan sobre todo en los derechos fundamentales- establecen un tipo de validez jurídica que ya no es puramente formal. Los derechos fundamentales sancionados constitucionalmente son fuente de legitimación (o deslegitimación) y de justificación (o invalidación) del derecho positivo, motivo por el cual en el Estado constitucional de derecho cae esa 'presunción de legitimidad' de que se beneficiaba el derecho positivo. Por lo mismo, el Estado constitucional de derecho o democracia sustancial desciende de la

\footnotetext{
de lo que excede por arriba y por abajo, es decir, de los principios y de los casos. El derecho debería asentarse sobre lo que queda en medio, las reglas" (pp. 144-145).

${ }^{16}$ Cf. Zagrebelsky (1995), pp. 145-146.

${ }^{17}$ Cf. Zagrebelsky (1995), p. 151.

${ }^{18}$ Cf. Zagrebelsky (1995), p. 152.

${ }^{19}$ Cf. Zagrebelsky (1995), p. 153.

${ }^{20}$ Cf. Ferrajoli (2011), pp. 774-776.
} 
filosofía contractualista ${ }^{21}$. Y esto es así tanto porque las constituciones son pactos positivos, escritos, cuanto también porque la democracia se legitima desde la base por el consenso de los asociados, un consenso "que tiene como cláusula y como 'razón social' la garantía de los derechos fundamentales, cuya violación por parte del soberano legitima la ruptura del pacto, hasta la insurrección y la guerra civil”22.

Ferrajoli trata el Estado constitucional de derecho como un Estado de derecho paradigmático en el que predominan los principios positivos de justicia ${ }^{23}$. Esta sustancialización de las leyes supone todo un tránsito y un cumplimiento: el tránsito que va desde el principio de mera legalidad del positivismo jurídico hasta el principio de estricta legalidad ya pospositivista del constitucionalismo jurídico, con lo que se cumpliría jurídicamente la modernidad. La constitución, ahora, es un sistema positivo de normas metalegales que, si es democráticamente producido, define lo que las mayorías legislativas no pueden decidir o no pueden dejar de decidir, cosa que hace mediante la fijación convencional, contractual o artificial de normas de protección de los derechos fundamentales. El iusconstitucionalismo, a diferencia del iusnaturalismo y del iuspositivismo, es la idea del derecho de las modernas democracias constitucionales ${ }^{24}$. La definición de la constitución democrática es, así, también axiológica, pues incluye los derechos políticos (=democracia política), los derechos civiles (=democracia civil), los derechos de libertad (=democracia liberal) y los derechos sociales (=democracia social) ${ }^{25}$.

\section{Visiones GERMÁNICAS DE LA JUSTICIA CONSTITUCIONAL}

9. En la órbita alemana suele hablarse de la constitucionalización material del sistema jurídico, incluso del riesgo de su sobreconstitucionalización. En

${ }^{21}$ Cf. Ferrajoli (2011), p. 775.

${ }^{22}$ Cf. Ferrajoli (2011), p. 776.

${ }^{23}$ Cf. Ferrajoli (2011), pp. 801-906. Dice por ej.: "las condiciones sustanciales de validez de las leyes, que en el paradigma premoderno se identificaban con los principios del derecho natural y que en el paradigma paleopositivista fueron sustituidas por el principio puramente formal de la validez como positividad, penetran nuevamente en el derecho, gracias a este tercer paradigma, bajo la forma de principios positivos de justicia, o sea, de principia iuris et in iure, estipulados en normas supraordenadas a la legislación" (p. 802).

${ }^{24}$ Cf. Ferrajoli (2011), pp. 802-803.

${ }^{25}$ Cf. Ferrajoli (2011), pp. 841-846 y 879-884. 
efecto, la sobreconstitucionalización material estaría envuelta en los derechos fundamentales entendidos como valores y principios situados en la máxima jerarquía del sistema jurídico. El debate al respecto remonta a Kelsen, Schmitt, Heller, Smend y Forsthoff ${ }^{26}$, y en su forma más actual -incluyendo no sólo la cuestión de la justiciabilidad de las leyes y otras normas democráticamente producidas, sino también la de la ponderación como forma judicial de resolución de las colisiones entre tales derechos o valores superiores del orden jurídico- es conducido por una serie de constitucionalistas y filósofos del derecho (y, claro, por el mismísimo BVerfGE, al menos desde su célebre fallo del caso Lüth en $1958)^{27}$. La actual discusión alemana suele llevarse a cabo menos históricamente que en Italia, pero con mayores matices teóricos, pues se desarrolla sobre todo en el campo de la teoría constitucional y de toda una dogmática de los derechos y la deferencia hacia el legislador ${ }^{28}$.

10. Habermas conoce perfectamente las tensiones entre democracia y constitucionalismo, como también conoce la clásica discusión sobre la justicia constitucional entre Schmitt y Kelsen. Respecto de las prevenciones que efectuaron ambos y más recientemente Böckenförde a una jurisprudencia constitucional y a unos derechos fundamentales de prestación social que desdibujan al Estado liberal de derecho, Habermas contesta diciendo que el contexto del

\footnotetext{
${ }^{26}$ Especialmente conviene no olvidar la polémica entre C. Schmitt y H. Kelsen; cf. SchmitT y KeLSEN (2009). La argumentación de Schmitt contra el 'legislador negativo' de Kelsen (cf. pp. 322-325) ya es clásica: si los problemas políticos no son justiciables, entonces lo que la "ficticia judicialidad" constitucional acarrea inevitablemente es una politización de la justicia (cf. pp. 41-42 y 126), toda ella sustentada en esta lógica equívoca: "justicia es aquello que hace un juez, y, por consiguiente, todo cuanto hace un juez es justicia; el juez es independiente, luego todo aquel que es independiente es un juez; por consiguiente, todo cuanto hace un organismo independiente bajo la égida de su independencia, es justicia; ergo basta someter todos los pleitos constitucionales y divergencias de opinión al juicio de jueces independientes, y tendremos una 'justicia constitucional”" (p. 69).

${ }^{27}$ Cf. BVerfGE 7, 198. Vid. un extracto de este fallo en Schwabe (2009), pp. 202-207.

${ }^{28}$ La dogmática constitucional alemana es, por cierto, muy diversa. E. Böckenförde por ej. es crítico de la noción de Estado social de derecho, entre otras razones porque la constitucionalización material que implica conduce a la inseguridad jurídica y a abrazar un orden objetivo de valores -al modo como lo ha asumido el tribunal constitucional federal alemán- racionalmente inmanejable; cf. BÖCKENFÖRDE (2000), pp. 40-44. P. Häberle, otro ej., no suele enfocar muy claramente la tensión entre democracia y jurisdicción constitucional, porque así como la admite (y es que la constitución es restricción del poder), agrega que el tribunal constitucional tiene una legitimación democrática indirecta (no es guardián de la constitución, que eso lo es cada ciudadano, pero sí participante del contrato social, tribunal ciudadano y protector de las minorías): vid. HÄberle (2002), p. 163, y (2004), pp. 163-166 y 169. Vid. además Dreier (1991), pp. 85-97.
} 
Estado liberal ha desaparecido y que en el actual ámbito constitucional son insoslayables los principios jurídicos de universal obligatoriedad (Dworkin), definiciones de los derechos fundamentales abstractas, abiertas y cargadas de ideología al modo de bienes o valores jurídicos optimizables según su peso respectivo (Alexy), conceptos clave (Denninger) o normas de fondo (Sunstein), y que estos han de ser interpretados (como auspicia Dworkin) no formalística sino moral y constructivamente ${ }^{29}$.

A la vez, Habermas presenta y evalúa dos alternativas: o un control de constitucionalidad radicado en el propio órgano legislador -por ej. mediante una comisión parlamentaria compuesta por expertos en derecho- y que tendría la ventaja de procurar una autorreflexividad constitucional en el proceso legislativo, o un control efectuado por un tribunal constitucional externo al parlamento y por tanto constitutivo de una cierta heterorreflexividad constitucional. Claro, el problema con la heterorreflexividad de un tribunal constitucional que llega a crear políticamente normas jurídicas es su falta de legitimidad democrática ${ }^{30}$. Habermas cita a Ely, que también hace la distinción entre una aproximación deontológica y otra teleológica a los derechos fundamentales, y que ha justificado la jurisdicción constitucional con una aproximación escéptica y procedimental: semejante tribunal debería velar por la constitucionalidad en la medida en que vela por las condiciones procedimentales de la génesis democrática de las leyes. Pero, dice Habermas, esta aproximación esconde, aunque no lo admita, una teoría de la democracia y de los principios con evidente contenido normativo ${ }^{31}$.

Habermas comparte el republicanismo de Michelman, pero despojándolo de su idealismo (ese que tiende a identificar ética y política), y quedándose con su énfasis -el mismo que pone la teoría del discurso- en una noción intersubjetiva del derecho y la política. Es cierto que la justicia constitucio-

\footnotetext{
${ }^{29}$ Que los derechos fundamentales sean principios de carácter deontológico o valores de naturaleza teleológica, esto es, normas de aplicabilidad binaria y universal o bienes de cumplimiento gradual y culturalmente particular, es un asunto capital, dice Habermas. La jurisprudencia constitucional alemana tan centrada en un orden objetivo de valores, en este sentido, padece de una inevitable arbitrariedad o al menos irreflexividad. Parece mejor la idea -discursivamente fundada y en la línea constructiva de Dworkin y Günther- de una obligatoriedad universalizable que jurídica y constitucionalmente se verifica como adecuación, coherencia y una única respuesta correcta para cada caso. Cf. HABERMAS (1998), pp. 326-334.

${ }^{30}$ Cf. Habermas (1998), pp. 313-326.

${ }^{31}$ Cf. Habermas (1998), pp. 336-340.
} 
nal sólo tiene una autoridad democráticamente derivada, pero también que puede ser defendida por su contribución a una política que genera normas deliberativamente, es decir, no por mera agregación de preferencias que se expresan, sino mediante el duelo justificatorio de razones que se argumentan. Precisamente la democracia deliberativa, obsesionada con la protección de la autonomía tanto privada como pública y de una comunidad política amenazada no solamente por la violencia estatal sino también por la potencia mercantil y la tiranía de los intereses particulares, podría brindar legítimo sustento a la peculiar aplicación del derecho que caracteriza a un tribunal constitucional. Es necesario, en todo caso, no considerar a este tribunal paternalísticamente (es un riesgo del republicanismo), como si fuese un pedagogo que enseña a mantener el espacio público y político en épocas de crisis. Habermas sostiene, en cambio, que este tribunal debería ser entendido comunicativa y procedimentalmente, en el marco de sociedades plurales en las que ninguna eticidad sustancial es consensuada en el fondo, al modo de un mediador normalizado entre facticidad y validez, de un vigilante del proceso democrático, de un protector estricto - a veces un tutor activo- de las reglas y principios de la deliberación ${ }^{32}$.

11. Alexy coincide parcialmente con Habermas. Ante todo trata de refutar las concepciones ingenuas que no creen que pueda haber conflicto entre democracia y derechos fundamentales:

"tanto los derechos fundamentales como la democracia son algo bueno y ¿cómo podrían entrar en conflicto dos cosas buenas? La concepción ingenua sostiene consecuentemente que se puede tener ambas juntas sin límite alguno. Esta visión del mundo es demasiado bella para ser verdad" 33 .

También se separa de las concepciones idealistas, de raíz rousseauniana, para las cuales, no real pero sí regulativamente, los derechos fundamentales y la democracia han de poder reconciliarse. Es el sueño, el símbolo de una sociedad bien ordenada a la que las sociedades existentes deben tratar de aproximarse: "en ella el pueblo y sus representantes políticos no están en absoluto interesados en lesionar los derechos fundamentales de ciudadano alguno por medio de decisiones parlamentarias mayoritarias, y por tanto de leyes, sino todo lo contrario" 34 .

32 Cf. Habermas (1998), pp. 340-360.

33 Alexy (2003a), p. 37.

${ }^{34}$ Alexy (2003a), pp. 37-38. 
Según Alexy hay otra concepción, la realista, que sí advierte conflictos entre derechos fundamentales y democracia: los derechos fundamentales serían democráticos porque protegen la libertad y la igualdad de las personas mediante garantías que estabilizan el proceso democrático y aseguran las condiciones para su funcionamiento, pero serían también antidemocráticos porque desconfían del legislador sometiéndolo a una jurisdicción de carácter constitucional que puede anular las decisiones de la mayoría parlamentaria.

Así, confiar los derechos fundamentales a una protección estrictamente democrática parece pecar contra ese realismo:

"ello implicaría que el legislador parlamentario quedara sujeto exclusivamente a un control interno, procedente del propio parlamento, y a la censura de la opinión pública. Siendo el mundo tal y como es, no podría excluirse que el poder público encargado de la tutela y realización de los derechos fundamentales (el propio legislativo) no fuera el primer infractor de los citados derechos. Para evitar en la mayor medida posible que esto ocurra, debe institucionalizarse el control de constitucionalidad"35.

Surge precisamente entonces la diferencia entre una representación política como la parlamentaria y una representación argumentativa como la de la jurisdicción constitucional, dos formas de representación distintas, pero no necesariamente contrapuestas sino reconciliables:

"hay que plantearse, pues, qué es aquello que ciudadanos racionales con concepciones personales del bien distintas consideran como condiciones de cooperación social justa tan importantes como para que el simple legislador no pueda decidir sobre ello [...] Un tribunal constitucional que intente responder seriamente no pretenderá situar su concepción en contra de la del legislador, sino que más bien aspirará a una representación argumentativa de los ciudadanos por oposición a su representación politica en el parlamento" ${ }^{36}$.

De modo que al encargar a una corte constitucional la representación argumentativa de los ciudadanos, aunque se corran riesgos, es posible contrarrestar la posibilidad -también riesgosa- de que un parlamento democrático afecte las propias condiciones de funcionamiento de la democracia o los derechos fundamentales:

35 Alexy (2010), p. 40.

36 Alexy (2003a), p. 40. 
“¿qué sucede si se aprueban leyes que vulneran los derechos fundamentales, o que son incompatibles con los principios de la democracia deliberativa? Se puede entonces o confiar en el poder de auto-sanación de la democracia o instituir una jurisdicción constitucional. Es preferible lo segundo. Toda jurisdicción constitucional, desde luego, encierra el riesgo de un paternalismo incompatible con la idea de autodeterminación democrática. Pero el riesgo puede contrarrestarse si la jurisdicción constitucional se concibe como la representación argumentativa de los ciudadanos y si, en cuanto tal, tiene éxito" ${ }^{\prime 3}$.

Así, si los derechos fundamentales tienen máxima fuerza jurídica, máximo rango y máxima importancia por su objeto, son también principios máximamente indeterminados cuyo choque o colisión tiene que ser ponderado en cada caso -y de ahí que Alexy haya elaborado al respecto, separándose de Habermas, toda una estructura ponderativa conforme a cierta fórmula del peso ${ }^{38}$. Esto significa, por otra parte, que la constitución puede y tiene que ser entendida simultáneamente como orden marco -porque efectivamente prohíbe y ordena unas cuantas acciones, mas también estipula un ámbito de acción discrecional donde no prohíbe ni ordena-y fundamental -en la medida en que, cualitativamente hablando, sólo resuelve asuntos básicos de la convivencia prohibiéndolos y ordenándolos, mientras deja abiertos todos los demás, reservados por ende a las decisiones democráticas del legislador y en general de los poderes públicos ${ }^{39}$. Esa deferencia para con los poderes públicos implica, en todo caso, elaborar una dogmática tan desarrollada como sea posible de estos márgenes de acción, esto es, de las posiciones libres o discrecionales - unas estructurales, otras epistémicas, dirá Alexy- que la constitución (justo por no prohibir ni ordenarlo todo) confía a los poderes públicos ${ }^{40}$.

\section{CONSTITUCIONALISMO ESTADOUNIDENSE Y JUDICIAL REVIEW}

12. Pero la cuna del constitucionalismo no está en Italia ni en Alemania, países de tardías e interrumpidas democracias constitucionales, sino en las islas británicas y, con el ingrediente de una constitución escrita, en los EE.UU. En esta federación nació el judicial review en 1803 con el razonamiento del juez

\footnotetext{
${ }^{37}$ Alexy (2009), p. 80.

${ }^{38}$ Cf. Alexy (2003a), pp. 32-37 y (2008), pp. 349-374.

39 Alexy (2003b), pp. 54-56.

${ }^{40}$ Cf. Alexy (2003b), pp. 52 y 57-58 y 58-87.
} 
Marshall fallando el caso Marbury v. Madison ${ }^{41}$, desarrollándose además una intensa reflexión a su respecto, como lo muestran ya las opiniones discrepantes de A. Hamilton, J. Madison y Th. Jefferson ${ }^{42}$, o lo que decía, a mediados del siglo XIX, A. de Tocqueville ${ }^{43}$, o lo que han discutido, desde la segunda mitad del siglo XX, estudiosos como A. Bickel, J. Hart Ely, R. Dahl, J. Rawls, L. Tribe, S. Holmes, B. Ackerman, R. Dworkin, J. Waldron, L. Kramer, R. Fallon, Jr. y B. Friedman, de lo cual haré muy sucinta revisión.

13. Un filósofo tan influyente como Rawls, sin abordar detalladamente el puesto de la justicia constitucional en una democracia, ha aportado reflexiones de interés. La libertad política, dice en Una teoría de la justicia, es tanto más extensa cuanto mayor sea el grado de mayoría establecido constitucionalmente. Lo que hace una constitución es aminorar ese grado de influjo de la regla mayoritaria. Según Rawls, tal afectación de la libertad política, siempre que sea igual para todos, puede ser congruente con el constitucionalismo ${ }^{44}$. Vale decir, una

${ }^{41}$ Cf. 5 US (1 Cranch) 137. Vid. el texto casi completo de la sentencia en Beltrán y GonZÁlez (2006), pp. 99-121.

${ }^{42}$ Vid. El Federalista No78 y los párrafos al respecto en PÁramo (2002), pp. 447-448.

43 Vid. Tocqueville (2005): "los americanos han reconocido a los jueces el derecho de fundamentar sus decisiones en la Constitución más que en las leyes. En otros términos, se les permite la no aplicación de las leyes que les parezcan inconstitucionales": p. 156. Y esto es algo que reconocerían todos los poderes, partidos y hombres en EE.UU. La constitución allí no es inmutable -como en Francia- ni puede ser alterada ordinariamente por el parlamento -como en Inglaterra- (cf. pp. 156-157). Es la primera de todas las leyes, y aquella a la que han de obedecer preferentemente los jueces. Por eso es enorme el poder político de los tribunales americanos: porque pueden, en cierto modo por derecho natural, escoger las leyes que mejor desarrollan a la constitución y por ende no aplicar en un proceso leyes inconstitucionales. Este gran poder está, con todo, limitado, pues los jueces sólo pueden atacar las leyes por medios judiciales (cf. pp. 154 y 158-159; "no juzga la ley más que por estar obligado a juzgar un proceso, y no puede abstenerse de enjuiciar en un proceso": p. 160). Claro que si el control judicial de constitucionalidad de las leyes fuese un poder que se ejerciese espontánea y generalmente, y no pasiva y particularmente como en EE.UU., entonces el juez se volvería un faccioso, "habría entrado brillantemente en la escena política, y convertido en campeón o en adversario de un partido, habría apelado a todas las pasiones que dividen al país para tomar parte en la lucha" (cf. p. 159). Pero, la manera específica de actuar del poder judicial norteamericano es quizá si la más favorable al orden público y a la libertad. Por ello, siendo el judicial un poder considerable, es de todas formas una de las barreras contra la tiranía de los parlamentos, contra la omnipotencia democrática, contra la tiranía de la mayoría (cf. sobre todo pp. 159-160 y 357-398). Para Tocqueville, es indudable que debe haber un poder superior, soberano, sin embargo de lo cual, jamás hay que admitir un poder sin límites. Como otras formas de poder, también la soberanía popular ilimitada, inmoderada, omnipotente, es un peligro para la libertad. De hecho, esto es lo que más repugna a Tocqueville de la democracia en EE.UU.: "la poca garantía que existe contra la tiranía [de la mayoría]" (cf. p. 365; cf. pp. 367 y 375-376).

${ }^{44}$ RAWLS (2006a), pp. 212-213. 
"libertad de participación menos extensa está suficientemente compensada por la mayor seguridad y extensión de las otras libertades". La justificación de las restricciones democráticas, entonces, descansa no en beneficios sociales o económicos, sino en "una mayor libertad igual" 45 . Todo esto es gradual, pues la decisión respecto de las restricciones democráticas no es total, sino un asunto de 'más o menos'. Es lo que hace una constitución: "un balance general de justicia". Y lo hace siempre contextualmente, en el entendido de que "todo depende de la probable justicia del resultado". Así, por ej.,

"si los diferentes sectores de la sociedad tienen suficiente confianza entre sí, y comparten una concepción común de la justicia, el gobierno de las simples mayorías puede funcionar bien. En la medida en que falta este acuerdo implícito, el principio de mayorías se hace más difícil de justificar porque es menos probable que se sigan programas políticos justos" ${ }^{36}$.

En Liberalismo político, años después, Rawls aborda este mismo asunto a partir de la noción de 'razón pública'. Afirma que "[...] en una sociedad democrática, la razón pública es la razón de ciudadanos en pie de igualdad que, como cuerpo colectivo, ejercen el poder político final y coercitivo unos sobre otros, al poner en vigor las leyes y al hacer enmiendas a su constitución" ${ }^{47}$. En un régimen constitucional, dice Rawls siguiendo de cerca a Elster y Ackerman, la razón pública es la razón de la corte suprema en la medida en que esta es el más alto intérprete judicial -no el último intérprete, cosa diferente- de la constitución, y la corte suprema es además el órgano público que encarna y visibiliza ejemplarmente esa razón pública ${ }^{48}$. La suprema interpretación constitucional la ejercen los tres poderes públicos según las relaciones que especificadamente guardan entre sí, y siempre responsablemente ante el pueblo. No hay procedimiento constitucional que inmunice contra cambios lesivos o abusivos para los derechos y la democracia. El judicial review no es antidemocrático. Puede ser contramayoritario respecto de la legislación ordinaria, pero no respecto de la ley más alta, la constitucional. La labor de interpretación constitucional de una corte suprema ha de asentarse en los valores y principios políticos de la razón pública.

45 RAWLS (2006a), p. 217.

${ }^{46}$ RAWls (2006a), p. 218.

${ }^{47}$ RAWLS (2006b), p. 205.

${ }^{48}$ Cf. RaWls (2006b), pp. 219-220. 
Hay, es cierto, otras alternativas a este modelo dualista con judicial review: el modelo de la supremacía parlamentaria o de Westminster y el alemán de la intangibilidad de ciertos derechos garantizados. El modelo dualista requiere que la corte suprema realice su tarea de acuerdo con una variante razonable de la concepción política de la justicia, y no con su propia moral personal, ni con la moralidad general, ni siquiera con puntos de vista religiosos o filosóficos. Así y sólo así es como en cada caso trata de entregar razones para la mejor interpretación posible de la constitución. Estas discusiones judiciales otorgan vivacidad y valor pedagógico a la razón pública de principios ${ }^{49}$. Pero no permite decir que la constitución sea lo que la corte dice que es; la constitución sólo es "[...] lo que el pueblo, actuando constitucionalmente a través de las otras ramas del poder, permite a la corte suprema decir al respecto" ${ }^{50}$. ¿Tiene límites la capacidad de cambio democrático de la constitución? ¿Podría por ej. derogarse la primera enmienda de la constitución norteamericana? Rawls responde que no. Las enmiendas válidas permiten ajustar valores políticos fundamentales a las cambiantes circunstancias o bien incorporar a la constitución una intelección más panorámica e incluyente de los valores y principios constitucionales, pero restringen las posibilidades del cambio al excluir la validez de modificaciones revolucionarias que harían derrumbarse los elementos constitucionales básicos. De todos modos, Rawls no pretende defender el judicial review a toda costa, sino sólo contextualizadamente, en ciertas circunstancias históricas y de la cultura política ${ }^{51}$.

14. Dworkin es un filósofo del derecho muy influenciado por Rawls. Afirma que éste no apoyó la objeción democrática a la justicia constitucional, que el modelo estadounidense de judicial review no es la única manera de proteger las libertades básicas y, en fin, que de todas formas ese modelo puede

\footnotetext{
${ }^{49}$ Cf. RaWls (2006b), pp. 221-225 y 227.

${ }^{50}$ Cf. RaWls (2006b), pp. 225-226.

${ }^{51}$ Cf. RaWls (2006b), pp. 226-227. En las póstumas Lecciones sobre la historia de la filosofía política, Rawls asegura que aceptar el control judicial de constitucionalidad supone que "[...] una constitución democrática coloque ciertos derechos y libertades fundamentales fuera del dominio de las mayorías legislativas de la política cotidiana (que no de la constitucional). Yo me inclino a aceptar el control judicial de la constitucionalidad en nuestro caso, pero ambos bandos tienen buenos argumentos y la cuestión debe ser considerada por los propios ciudadanos democráticos. Lo que se dirime aquí es una elección entre dos concepciones de la democracia: la democracia constitucional y la mayoritaria. En cualquier caso, quienes apoyan el control judicial de la constitucionalidad dan por sentado que, en la política cotidiana, las mayorías legislativas son las que normalmente gobiernan”: (2009), pp. 31-32.
} 
ser razonablemente apoyado por ser consistente con la soberanía popular (es lo que Rawls cree siguiendo a Ackerman: el pueblo apoyó la constitución original y ha sustentado las decisiones cardinales de la Corte Suprema) y por ser favorable al desarrollo de las capacidades morales de un sentido de la justicia y de una concepción de lo bueno (la Corte Suprema americana actúa como foro de principios y así ayuda a centrar la discusión pública de los problemas morales) ${ }^{52}$. Desde su propia perspectiva, dice Dworkin que "la fidelidad a una constitución moral no supone que los jueces deban ser los árbitros últimos de lo que tal constitución exige en las concretas circunstancias" 53 . Pero en los EE.UU. son precisamente los jueces quienes velan por la constitucionalidad de las leyes por fidelidad a la constitución. ¿Es esto democrático? Depende de lo que se entienda por democracia.

Si se maneja una idea estadística de democracia -la democracia como aquel régimen en que las cuestiones de principio se deciden por mayoría-, entonces el control judicial es antidemocrático. Mas, si se tiene un concepto de democracia como empeño comunitario, cooperativo e integrado -no monolítico- de autogobierno, entonces ese control judicial puede no tener rasgos antidemocráticos. Y es que en tal caso "la regla de la mayoría es democrática sólo cuando se dan y se mantienen ciertas condiciones previas: las condiciones democráticas de la igual membresía" "4. ¿A qué se refiere Dworkin? A tres cosas que, como se verá, tienen relación tanto con las condiciones como con los resultados -la corrección o incorrección de las respuestas- del proceso democrático ${ }^{55}$. Primero, al principio de participación (garantizado por la primera enmienda americana): todo ciudadano debiera tener "[...] la oportunidad de desempeñar un igual papel en la vida política, lo que no sólo significa un igual derecho de voto, sino una igual voz en las deliberaciones públicas formales y en los intercambios morales informales". Segundo, al principio de interés (garantizado por la cláusula de igual protección): en el interés general o colectivo debe contar y considerarse igualmente el interés de cada cual. Tercero, al principio de independencia (garantizado por la primera enmienda cuando esta custodia la libertad religiosa y por la cláusula del debido proceso), según el cual el juicio moral y ético es de

\footnotetext{
52 Dworkin (2007a), pp. 278-279.

53 DwOrKin (2007b), p. 151.

${ }^{54}$ Dworkin (2007b), p. 151. Más detalles en Dworkin (2010), pp. 123-135.

55 Que Dworkin ha detallado, entre otros lugares, en (1996), pp. 24 y ss., en (2007b), pp. 135-143, y en (2008), pp. 167-185.
} 
responsabilidad propia, de modo que cada individuo tenga una esfera privada protegida para tomar decisiones en conciencia ${ }^{56}$.

Así, el control judicial no es incoherente con la democracia comunitaria, sin que sea tampoco necesario para garantizarla: "bien se puede pensar que habría sido mejor residenciar tal responsabilidad en un órgano especialmente elegido y que la decisión de otorgársela a jueces no electos que se tomó o ratificó en el siglo XIX fue imprudente" ${ }^{57}$. De hecho, dice Dworkin, es razonable rechazar el control judicial como control último y autoritativo de constitucionalidad $^{58}$. No obstante lo cual, afirma enérgicamente que "en la concepción comunitaria, la democracia y las restricciones constitucionales no son antagonistas, sino que, en principio, van de la mano"59.

15. Dahl es un cientista político que ha dado cobertura teórica a la objeción democrática, señalándola como motivo para desconfiar de la legitimidad política de la justicia constitucional. Ha dicho, en efecto, que por medio del control judicial se protegen del proceso democrático algunas decisiones sobre derechos e intereses básicos, poniéndolas en manos de unos funcionarios -los jueces constitucionales- a los que por eso cabría denominar 'cuasi-tutores'. El judicial es la forma más usual de controlar el proceso democrático, pero no la única $^{60}$. EE.UU. es quizá el ejemplo más puro de ese control judicial. En efecto, para proteger los derechos e intereses básicos "[...] en la mayor parte de las poliarquías estables los ciudadanos confían básicamente en el proceso democrático tal como se corporiza en el parlamento, las elecciones y, a veces, los referendos nacionales", pero en EE.UU. se suele dar por sentado, incluso entre abogados, "[...] que la existencia de un poder judicial vigilante, dotado de la facultad de revocar las políticas nacionales adoptadas por la legislatura y por el ejecutivo, es esencial para preservar los derechos fundamentales" ${ }^{\prime 6}$.

Varias afirmaciones, a juicio de Dahl, pueden hacerse en torno a este tema, dentro de las cuales se destacan las que siguen. Ante todo, hay una relación inversamente proporcional entre el poder del demos y el poder de los cuasi-

${ }^{56}$ DwOrKIN (2007b), pp. 151-152.

${ }^{57}$ Dworkin (2007b), p. 152.

${ }^{58}$ DWORKIN (2007c), p. 71.

${ }^{59}$ DwOrKIN (2007b), p. 149.

${ }^{60}$ Cf. Dahl (1991), p. 226.

${ }^{61}$ DAHL (1991), p. 227. 
tutores, de manera que mientras más amplio y activo sea el poder de los jueces constitucionales -llegando incluso a elaborar detalladas políticas públicas-, menos amplio y activo será el poder propiamente democrático. Luego, resulta difícil argumentar que el judicial review sea indispensable; para ello habría que mostrar que los países sin judicial review son menos democráticos o menos protectores de los derechos fundamentales que los países donde sí hay control judicial de constitucionalidad. La autorrestricción del demos y de sus representantes sería más necesaria allí donde no hay cuasi-tutela judicial, y menos donde sí la hay. Y parece beneficioso para una cultura política que la actitud de autorrestricción se consolide popular e institucionalmente ${ }^{62}$. Enseguida, atendiendo a las peculiaridades estadounidenses, Dahl asegura que los jueces no han sido demasiado protectores de los derechos fundamentales frente a un demos abusivo y unos representantes avasalladores. La Corte Suprema no se ha distinguido siempre por su apoyo a las minorías o a los más débiles. La Corte Suprema, dice Dahl, inevitablemente se ha aliado con cada mayoría política electoral, vale decir, con la que sustenta al presidente o se expresa en la mayoría del senado: "los puntos de vista de la mayoría de los jueces que integran el alto tribunal nunca discrepan por mucho tiempo de los prevalecientes entre la mayoría que elabora las leyes" ${ }^{33}$. Así, los cuasi-tutores judiciales no suelen ser garantes de los derechos fundamentales frente a las mayorías democráticas, salvo y sólo quizá en el corto tiempo. Y no lo son porque si se aislaran prolongadamente de la opinión pública mayoritaria terminarían perdiendo legitimidad política.

La única manera, cree Dahl, de justificarse el cuasi-tutelaje judicial es la de restringirlo, como pide Ely, a la protección de los intereses y derechos básicos que son condiciones integrales del, e inherentes al, proceso democrático; pero, a medida que los intereses y derechos que se intenta proteger se alejan del proceso democrático por no ser estrictas condiciones procesales del mismo, la legitimidad del judicial review decrece e incluso desaparece, reduciéndose con él los alcances del poder democrático. Es crucial, dice Dahl, captar que el conflicto entre democracia y control judicial de constitucionalidad no es uno entre procedimiento y resultados, o procesos y derechos, estando la democracia del lado procesal y el constitucionalismo judicial del de los derechos. Este es en verdad un conflicto entre derechos fundamentales, pues en

${ }^{62}$ Cf. Dahl (1991), p. 228.

${ }^{63}$ DAHL (1991), p. 229. 
el proceso democrático está en juego el fundamental derecho político de las personas a autogobernarse ${ }^{64}$. Que un derecho sea democráticamente inviolable o que juez defienda un derecho individual 'contra el Estado', es una manera de hablar que puede ocultar que aquí hay una colisión de derechos, y una en la cual el juez también puede decidirse equivocadamente lesionando un derecho fundamental.

Sea de ello lo que fuere, la conveniencia o inconveniencia del judicial review ha de juzgarse in concreto, tomando en cuenta la historia y la cultura política e institucional de cada poliarquía. En todo caso, hay que considerar especialmente los valores que respaldan al proceso democrático y las consecuencias empíricas de la adopción de un mecanismo no democrático:

"así pues, se precisan abundantes comprobaciones antes de reemplazar un proceso democrático por un cuasi-tutelaje. Habrá que demostrar que el proceso democrático no otorga una consideración equitativa a los intereses de algunos individuos sujetos a sus leyes, que los cuasi-tutores sí lo harán, y que el daño causado al derecho a la consideración equitativa supera con creces el daño causado al derecho de las personas a autogobernarse" ${ }^{65}$.

Y aun así, Dahl cree que, para sacrificar el proceso democrático en favor de cuasi-tutores judiciales, no ha de valorarse demasiado la responsabilidad moral y política, ya que si tal fuera el caso, entonces sería preferible un proceso en el que, pudiendo cometerse errores, se despliegue la autonomía:

"en la medida en que [el pueblo] es privado de la oportunidad de actuar en forma autónoma y es gobernado por tutores, es menos probable que desarrolle un sentido de responsabilidad por su proceder colectivo; en la medida en que sea autónomo, a veces se equivocará y actuará injustamente. El proceso democrático es una apuesta de que un pueblo, obrando en forma autónoma, pueda aprender a hacerlo correctamente" ${ }^{16}$.

${ }^{64}$ Cf. DAHL (1991), p. 230.

${ }^{65}$ DAHL (1991), p. 231.

${ }^{66}$ DAHL (1991), p. 232; vid. pp. 98-100. Este libro retoma una vieja preocupación de DAHL CUYA MANIFESTACIÓN MÁS DESCOLLANTE HABÍA SIDO (1957), pp. 279-295. En favor de esta vía, entendiendo que en ella pudieran coincidir tanto Ely como Habermas y una versión deliberativa de la democracia, vid. ZuRn (2007). Por otra parte, cabe ver en la perspectiva sensata, prudente y práctica de Dahl el concentrado de cuatro generalizaciones, que no leyes, a las cuales este otorga suma importancia política para defender la democracia frente a las diversas caras del tutelaje: una es la de Clemenceau (la guerra es una cosa demasiado importante como para dejarla en manos de los generales), otra la de 
16. Próximo a la perspectiva de Dahl y crítico con Rawls y sobre todo con Dworkin, Waldron ha escrito profusamente sobre el control judicial de constitucionalidad. ¿No es insultante, se pregunta, que los desacuerdos colectivos no se zanjen democráticamente, sino que sean encomendados a un puñado de jueces? ${ }^{26}$. A esto responde con un paralelo:

“compárese un parlamento con un tribunal. Un tribunal también está estructurado de tal manera que permite que las concepciones rivales estén representadas; se trata de una institución adversarial”"68.

Pero, en los tribunales las partes disputan ante un tercero imparcial, el juez, quien debe dirimir su desacuerdo, mientras que en los parlamentos no existe ese tercero que resuelva imparcialmente los conflictos. Unos y otros son diferentes, no obstante lo cual en ambos hay deliberación y voto mayoritario. No por votar se deja de deliberar, así como tampoco por deliberar se debe dejar de votar ${ }^{69}$.

Según Waldron, no es claro conceptual ni normativamente el tránsito desde la idea de los derechos -sean morales o ya jurídicos- hacia la de derechos constitucionalmente atrincherados. Más bien la noción de portador de derechos (rights-bearer) indica la dirección contraria:

"las razones que me hacen pensar en el ser humano como portador de derechos son las mismas razones que me permiten confiar en él como portador de responsabilidades políticas. Precisamente porque yo veo a toda persona como un potencial agente moral, dotado de dignidad y autonomía, desearía confiar al pueblo en masse la obligación del autogobierno"70.

Además, conviene cierta modestia al abordar el asunto de '¿quién decidirá qué derechos tenemos cuando todos estamos en desacuerdo?'. La arrogancia de la mentalidad constitucionalizadora tiende a atribuir las controversias

\footnotetext{
Murphy (si las cosas pueden empeorar, entonces probablemente empeorarán), la tercera la de Lord Acton (el poder tiende a corromper, y el poder absoluto, a corromper absolutamente) y la última la de Mill (nadie defiende mejor los derechos e intereses de cada cual que cada cual): vid. DAHL (1991), pp. 89-90 y 97.

${ }^{67}$ Cf. Waldron (2005), p. 23; vid. pp. 23-25.

${ }^{68}$ WALDRON (2005), p. 32.

${ }^{69}$ Cf. Waldron (2005), pp. 32-33 y 36.

${ }^{70}$ WALDRON (2005), p. 266; vid. pp. 258-266.
} 
sobre derechos a tribunales gobernados por una élite de hombres sabios, no a parlamentos donde discuten y deliberan los representantes del pueblo a quien afectarán las decisiones que se tomen ${ }^{71}$. El problema es que la participación es -Waldron cita la fórmula de Cobbett- 'el derecho de los derechos' ${ }^{\text {' }}$. Lo es no por tener alguna prioridad moral sobre los demás derechos, sino porque " $[. .$.$] es un derecho cuyo ejercicio parece peculiarmente apropiado$ en situaciones en las que los portadores razonables de derechos discrepan acerca de qué derechos tienen"73. El derecho a participar es, así, un derecho que permite afrontar los desacuerdos sobre derechos y que al mismo tiempo respeta los presupuestos morales y políticos en los que reposan aquel y estos derechos $^{74}$. De aquí brota una teoría de la autoridad basada en derechos-que no es fácilmente compatible con un instrumentalismo de los derechos- según la cual "[...] los portadores de derechos tienen el derecho a resolver por sí mismos los desacuerdos acerca de los derechos que poseen en términos de igualdad"75. Así, no es incompatible la idea de democracia con la de derechos humanos, ya que no hay democracia sin ese derecho de los derechos que es el de participar en la elaboración de las leyes. Derechos y democracia tienen una base común: "cuando identificamos a alguien como portador de derechos expresamos algún tipo de confianza en las capacidades morales de esa persona, en especial en su capacidad para pensar responsablemente sobre la relación moral entre sus intereses y los intereses de los demás" ${ }^{76}$. La objeción democrática al control judicial de constitucionalidad está, pues, también basada en derechos ${ }^{77}$.

Respecto de aquellos problemas de la comunidad toda, no parece defendible el control judicial por el dicho nemo iudex in causa sua, sino que parece aplicable más bien el argumento democrático que lo rechaza en virtud del quod omnes tangit ab omnibus decidentur ${ }^{78}$. Para Waldron, "[...] siempre se produce un me-

\footnotetext{
${ }^{71}$ Cf. Waldron (2005), p. 275.

72 Cf. Waldron (2005), pp. 277-303.

73 Waldron (2005), p. 277.

${ }^{74}$ Cf. Waldron (2005), p. 300.

75 WaLdRon (2005), p. 303.

76 Waldron (2005), p. 337.

${ }^{77}$ Cf. Waldron (2005), p. 338.

${ }^{78}$ Cf. Waldron (2005), pp. 354-355.
} 
noscabo para la democracia cuando una concepción sobre las condiciones de la democracia se impone mediante una institución no democrática, incluso cuando la concepción es correcta y su imposición mejora la democracia"79. Tampoco hay razón ni evidencia de que el judicial review mejore la deliberación pública, ni que por ende su ausencia empobrezca la justicia de una comunidad política. ¿Entonces está todo al alcance de nuestra mano en democracia? Waldron cree que sí, "[...] incluyendo los derechos asociados a la democracia misma" ${ }^{80}$. Parece peligroso admitir esto, pero a juicio de Waldron hay que controlar el pánico ante el autogobierno político. El desacuerdo en torno a principios y derechos no debiera limitarse constitucionalmente con algo como el control judicial, como lo ha asegurado la teoría del precompromiso, que quiere inmunizar a la comunidad contra la locura o la akrasia ${ }^{81}$. No sólo las mayorías democráticas, sino también los jueces constitucionales "[...] discrepan acerca de tales derechos tanto como los demás, y también resuelven sus desacuerdos por un voto de mayoría simple" 82 .

El argumento en pro de la democracia de Waldron, como se ve, es parecido al sentido de la autonomía y la responsabilidad defendido por Dahl: "si nos importa la libertad individual, entonces, la primera cosa que deberíamos hacer no es reclamar una carta de derechos para ser aplicada por un tribunal, sino desarrollar entre nosotros una cultura de la libertad que haga que los que participarán en las decisiones sociales y políticas más importantes aprecien y se tomen en serio esta idea de libertad" ${ }^{\prime 3}$. Tomar los derechos en serio, dice Waldron contra Dworkin ${ }^{84}$, supone encarar la alteridad social y el desacuerdo político con una adecuada teoría de la autoridad, sabiendo que cada cual es un agente moral y un portador de derechos que puede y debe participar igualmente en la determinación de las condiciones compartidas que requiere la vida en comunidad $^{85}$.

\footnotetext{
79 WaLdRon (2005), p. 361.

80 WaLdron (2005), p. 362.

${ }^{81}$ Cf. Waldron (2005), pp. 365 y 305-335.

82 Waldron (2005), p. 365.

83 WALDRON (2005), p. 370.

${ }^{84}$ Cf. Waldron (2005), pp. 251-254 y 338-361.

85 Cf. Waldron (2005), pp. 371-372. Otros textos posteriores de Waldron también pertinentes: (2006), (2008), (2009a) y (2009b).
} 


\section{DEMOCRACIA Y DERECHOS EN EL CONSTITUCIONALISMO IBEROAMERICANO}

17. Latinoamérica y España también han ido a la zaga de los EE.UU. en lo que toca a los problemas que el constitucionalismo judicial plantea al proceso democrático. Se advierten aquí intentos por encarar tales problemas, aunque sólo sea desde hace poco tiempo y dominando la adscripción a autores y estilos ya examinados, en unos casos a la manera anglosajona, en otros a la alemana (incluso a veces -a partir de la polémica neoconstitucionalista- a la manera italiana). Rawls, Dworkin, Habermas y Alexy son en todo caso autores especialmente seguidos en esta región. En cuanto al generalizado control judicial que aquí se realiza, quizá si los más relevantes sean el Constitucional español y el colombiano, ambos muy influidos por la práctica de su homónimo alemán. De todos modos, hay algunas reflexiones lúcidas y rigurosas que conviene mencionar.

18. Nino, en un libro póstumamente publicado, ha asumido el punto de vista de un modelo, el de la democracia deliberativa: "la superioridad moral de la democracia por sobre los sistemas dictatoriales de toma de decisiones colectivas radica en su mayor tendencia hacia la imparcialidad debido a que en ella existen mejores posibilidades de saber y evaluar los intereses de todas las personas afectadas" ${ }^{\prime 6}$. Por esto cree que el control judicial de constitucionalidad es por regla general ilegítimo, pues en una democracia constitucional deliberativamente modelada se producirían decisiones dotadas de valor epistémico, mientras que los jueces suelen carecer de legitimación democrática en las democracias constitucionales actuales ${ }^{87}$. Sin embargo, admite Nino, hay excepciones. Estas nada tienen que ver con alguna suerte de necesidad lógica derivada de la supremacía constitucional (como parece argumentar el juez Marshall en Marbury v. Madison) o en cuanto lógico requisito vinculado con el reconocimiento de los derechos (según el argumento de Dworkin) ${ }^{88}$. El control judicial sólo es legítimo en tres hipótesis, las dos primeras relacionadas con las precondiciones del proceso democrático, la última con la eficacia de las decisiones democráticas.

La primera, la de las precondiciones democráticas, es la especificada por J. Hart Ely: el control del cumplimiento de las reglas del proceso democrático

${ }^{86}$ Cf. Nino (1997), p. 291; vid. en gral. pp. 154-201.

${ }^{87}$ Cf. Nino (1997), pp. 258-261.

${ }^{88}$ Cf. Nino (1997), pp. 261-272. 
no puede encomendarse al mismo proceso, sino a unos jueces que hagan de árbitros ciudadanos del mismo y que, por ende, custodien los derechos a priori de los que depende la democracia ${ }^{89}$.

La segunda excepción se basa en el valor de la autonomía personal y admite por ende el control de constitucionalidad para derribar decisiones democráticamente generadas de carácter perfeccionista. Como cada cual debe ser libre de trazarse sus planes vitales y sus propios ideales de realización personal, entonces

"[...] la discusión y la toma de decisiones en forma colectiva no son en forma sustancial más confiables que la reflexión individual y la toma de decisiones para arribar a soluciones moralmente correctas en este sentido [...] En este punto, sólo el juicio de los individuos mismos resulta relevante. En consecuencia, un juez, o cualquier ciudadano con fundamentos para efectuar una objeción de conciencia, debería considerar y, eventualmente, poner a un lado cualquier ley perfeccionista u otras normas de origen democrático [...] La razón para no seguir los mandatos de una legislación perfeccionista es que su fundamento real es la imposición de un ideal de excelencia humana" ${ }^{\prime \prime}$.

Y la tercera posibilidad de admitir el control judicial consiste en preservar o asegurar una constitución histórica. Se trata aquí de una práctica constitucional que adolece de algunos inconvenientes morales, pero que está de todos modos suficientemente justificada a la luz de la constitución ideal de los derechos y del poder como para rechazar su transgresión aun cuando esta se verificara por decisiones democráticas:

"aunque no se vea violado ningún derecho si se mantuviera la decisión democrática, la práctica social constituida por la constitución histórica podría verse debilitada y, como resultado de ello, la eficacia de las decisiones democráticas podría resultar enormemente afectada. En esta situación el juez puede intervenir en forma justificada para invalidar la ley democrática a fin de proteger la convención constitucional que garantiza la eficacia de las decisiones democráticas mismas" 91 .

${ }^{89}$ Cf. Nino (1997), pp. 273-277; vid. una ilustración de esta excepción en el caso Griswold v. Connecticut (381 US 479, 1965): (1997), pp. 283-286.

${ }^{90}$ Cf. Nino (1997), pp. 278-279; vid. en gral. 277-280 y una ilustración de esta excepción en el caso Roe v. Wade (410 U.S. 113, 1973): (1997), pp. 286-290.

${ }^{91}$ Cf. Nino (1997), p. 281; vid. en gral. 280-282 y una ilustración a contrario de esta excepción en el caso Brown v. Board of Education (347 U.S. 483, 1954): (1997), pp. 290-291. 
Además, Nino promueve mejorar el fundamento democrático del órgano judicial encargado del control de constitucionalidad, así como expandir sus posibilidades de actuación, de manera que pueda también "adoptar medidas que promuevan el proceso de deliberación pública o la consideración más cuidadosa por parte de los cuerpos políticos [democráticos]", como por ej. declarando una inconstitucionalidad por omisión y requiriendo al parlamento de explicaciones por tal omisión y los planes previstos para superarla, o vetando suspensivamente una ley que finalmente el poder democrático puede-luego de una nueva deliberación y decisión- terminar imponiendo ${ }^{92}$.

19. Ferreres también admite que la justicia constitucional puede ser legítima. En su approach, analítico y de corte anglosajón como el de Nino, trata las tensiones que se producen entre justicia constitucional y democracia. Ante todo reconoce estos efectos 'contramayoritarios' -en la nomenclatura de Bickel- frente a los que han intentado negarlos de alguna manera. Y así como defiende la legitimidad de la rigidez constitucional y del control judicial de constitucionalidad, así también admite que (sobre todo la última) tiene inevitables costes democráticos. Los argumentos favorables a la rigidez y al control

92 Cf. Nino (1997), pp. 292-293. Diez años después, Martí prosigue estas reflexiones de Nino. La democracia deliberativa, dice, es un ideal regulativo cuyas propiedades (independientes entre sí) son dos: "[...] incluye una toma de decisiones colectiva con la participación de todos aquellos que resultarán afectados por la decisión, o de sus representantes: este es el aspecto democrático. A su vez, [...] esta decisión debe ser tomada mediante argumentos ofrecidos por y para los participantes, que están comprometidos con los valores de racionalidad e imparcialidad: y este es el aspecto deliberativo": MarTí (2006), p. 23 (Martí cita aquí a Elster). Pueden precisarse los principios estructurales y las (paradojales) precondiciones de la democracia deliberativa ideal; cf. (2006), pp. 90-97 y 108-127. Así como, ya desde el punto de vista de su puesta en práctica, cabe hablar de la república deliberativa en el sentido del diseño institucional más o menos detallado de la misma ("el sistema político que se infiere de adoptar una concepción republicana de la democracia deliberativa”: p. 2); vid. (2006), pp. 244 y 277-312. Justamente en cuanto al diseño, dice Martí, existen razones -razones por tanto que no pueden ser normativas, sino conceptuales o empíricas- para excluir asuntos de la deliberación democrática, y que justificarían esta exclusión cuando se trata de cuestiones políticas (paradigmáticamente las de la esfera privada, las cuales sin embargo han de ser determinadas inevitablemente por vías políticas), o bien tratándose de cuestiones políticas pero que debieran quedar al margen sea de la democracia (claro, fuera de la democracia ordinaria, pero nunca fuera de la democracia constitucional), sea de la deliberación (cuando por razones de coste fuera preferible emprender la negociación y el voto); vid. (2006), pp. 85-88. Martí aborda especialmente la posible legitimidad de la rigidez constitucional y del control judicial de constitucionalidad. Al respecto expone los argumentos usualmente enfrentados en (2006), pp. 285-291, y toma finalmente postura: salvando siempre la igualdad política de los ciudadanos a la hora de producir las decisiones públicas y autogobernarse, es posible mantener semejantes mecanismos por no ser forzosamente antidemocráticos, ni elitistas, ni refractarios a la deliberación: cf. Martí (2006), pp. 292-295. 
judicial tienen, pues, que exhibir que los buenos resultados instrumentales de ambos son mayores que sus costes democráticos ${ }^{93}$.

En favor de la rigidez (distinguiendo entre rigidez jurídico-formal, que existe cuando la modificación de la constitución exige un procedimiento más complicado que el legislativo ordinario, y esa rigidez contextual que pende de las circunstancias políticas, históricas y sociales $\left.{ }^{94}\right)$, Ferreres arguye la conveniencia de que derechos y libertades constitucionales estén redactados abstractamente (aunque no trivialmente), pues si no fuera así y estuviesen redactados detallada y categóricamente, existe el riesgo cierto de divorcio a lo largo del tiempo entre las garantías constitucionales y el consenso de valores vigente en la sociedad ${ }^{95}$. En pro del control judicial, a su vez, Ferreres invoca que tal proceso "[...] ejemplifica de manera especialmente refinada la práctica de argumentar en favor y en contra de las decisiones políticas a partir de razones derivadas de la constitución" ${ }^{\prime \prime}$, así como que con ocasión de dicho control judicial el debate puede enriquecerse con voces que no pudieron manifestarse en el proceso legislativo ${ }^{97}$.

Todo esto puede decirse más precisamente. La rigidez, ahora, puede justificarse de manera triple. Primero, como técnica que garantiza esa práctica que consiste en ofrecer y pedir razones ante la justicia constitucional en pro o en contra de la constitucionalidad de una ley ${ }^{98}$. Segundo, la rigidez se justifica porque equivale no a intangibilidad o atrincheramiento (aunque a veces llegue

\footnotetext{
93 Cf. Ferreres (2010), pp. 356-368. Los escritos de Ferreres, creo, afinan convenientemente algunos argumentos ya desplegados por autores como GARZón VAldés (1989), pp. 143-164, PÁramo (2002), y -con matices- Bernal Pulido (2005), entre otros. Un desarrollo más detallado y sofisticado de esta defensa de la justicia constitucional, sobre todo en la versión concentrada europea, y en todo caso consciente de sus costos democráticos, se halla en Ferreres (2007) y (2011).

${ }^{94}$ Ferreres (2002), pp. 228-230.

95 Cf. Ferreres (2002), pp. 230-231.

96 Cf. Ferreres (2002), p. 232.

97 Cf. Ferreres (2002), p. 233. De todos modos, debe admitirse que no es fácil que los jueces constitucionales cumplan con estos cometidos. El juez constitucional, en efecto, debe sintonizar con los valores socialmente consensuados, pero a la vez debe ser independiente de la presión de las mayorías sociales y parlamentarias para poder ser fiel a los principios constitucionales. El diseño de la institución judicial que ejerce el control de constitucionalidad ha de sopesar una y otra exigencia (por ej. tomando postura en materia de la duración del mandato de estos jueces), no siendo "[...] fácil indicar cuál es el punto de equilibrio adecuado", como lo muestran los ejemplos constitucionales estadounidense y europeo: cf. Ferreres (2002), pp. 233-234, y (2010), pp. 379-380.
}

98 Cf. Ferreres (2002), p. 234. 
a serlo), sino solamente a reformabilidad dificultada, y justo al no impedir sino sólo dificultar la reforma constitucional, esta reformabilidad especial viene a ser un medio de control de las interpretaciones de los jueces constitucionales ${ }^{99}$. Y tercero, la rigidez también permite una respuesta ya no constitucional sino específicamente legislativa a la declaración judicial de inconstitucionalidad, mediante la aprobación de una ley idéntica o semejante a la que fue antes invalidada, con lo que se trata de provocar un nuevo debate judicial con el objeto de modificar la anterior línea jurisprudencial ${ }^{100}$.

El control judicial de constitucionalidad puede justificarse por las ventajas que ofrece en comparación con el parlamento respecto de la protección tanto de los derechos procesales necesarios para el funcionamiento del proceso democrático (es la tesis de Ely), como también de derechos sustantivos (es lo que creen Habermas, Rawls y en cierto sentido Waldron). Por esto, piensa Ferreres, es que hay argumentos instrumentales sólidos para enfrentar la objeción democrática y que permiten "[...] justificar la expectativa de que los tribunales de justicia, mediante el control de constitucionalidad, pueden contribuir al mantenimiento de una cultura pública en la que los derechos fundamentales (tanto los procesales como los sustantivos) se toman en serio, de acuerdo con principios que se elaboran y aplican de manera consistente" ${ }^{101}$. Estos argumentos son de dos

\footnotetext{
99 De este modo, “[...] los órganos políticos deben poder 'responder' al juez a través de una reforma constitucional”: FERRERES (2002), p. 235. Hay quien cree que la rigidez es insuficiente y que la única solución sería la de la intangibilidad constitucional de los derechos, porque las mayorías tenderían estructuralmente al abuso y a la tiranía de las minorías. Según Ferreres, esto es más bien desmentido por la experiencia política, que muestra cómo los consensos mayoritarios pueden incluir derechos protectores de minorías, con lo que "[...] la rigidez constitucional, que protege pero no inmuniza, las interpretaciones judiciales frente a un juicio adverso de los órganos políticos representativos, no es una técnica insuficiente para proteger los derechos (en un mundo en el que nadie es infalible": Cf. FerReres (2002), p. 239.
}

${ }^{100}$ Cf. Ferreres (2002), p. 236. Esta razón justificatoria es distinta de otras formas de respuesta legislativa, como la del Reino Unido (" $[\ldots]$ donde ciertos tribunales tienen competencia para declarar la incompatibilidad entre una ley y la Human Rights Act de 1998, siendo el parlamento quien decide en último término si, a la vista de una declaración judicial de incompatibilidad, la ley debe ser modificada o no") y la de Canadá (“[...] donde se permite al parlamento aprobar una ley idéntica a la que fue invalidada por un juez, e inmunizarla frente a un ulterior control judicial, a través de una explícita declaración a tal efecto"): FERRERES (2002), p. 236. Y es una razón especialmente valedera allí donde hay parlamentos que -por no haber estructuras federales- concentran todo el poder legislativo y tribunales que practican un control abstracto y exclusivo de constitucionalidad: cf. FerReres (2002), pp. 237-238. Sobre las ventajas de la rigidez, vid. también FERRERES (2010), pp. 373-376.

${ }^{101}$ Cf. Ferreres (2010), pp. 372-373, en gral. pp. 368-373. 
tipos. Por una parte, los hay generales: los jueces tienen más tiempo que los legisladores para reflexionar sobre los principios constitucionales, están institucionalmente mejor predispuestos para apreciar y hacer respetar tales valores, y están forzados (“[...] en una cultura jurídica desarrollada”) a decidir con arreglo a principios razonables y no sólo por motivaciones particulares y contingentes. No es que por estas razones los jueces estén libres del yerro ni mucho menos; pero sí que respecto de los principios constitucionales son menos imperfectos que los legisladores ${ }^{102}$.

Por otra parte, hay argumentos instrumentales más específicos, en la medida en que son favorables a la jurisdicción constitucional centralizada para países de civil law: es un tribunal que puede examinar las cuestiones constitucionales con mayor tiempo y especialización que uno ordinario, con una dotación más amplia y plural de integrantes, con una mayor focalización en los problemas de filosofía política que suelen aquí estar en juego (dado que efectúa no sólo el control concreto sino también el abstracto de constitucionalidad), y que tiene la virtualidad de poder actuar motu proprio (lo cual "[...] es recomendable si se desea contar con una institución que actúe como contrapeso relativamente enérgico frente al legislador") y de provocar casi que la mayoría parlamentaria proceda más cuidadosamente (por la posibilidad de que recurran a él tanto individuos como una minoría de legisladores $)^{103}$.

20. Bayón, que sigue de cerca a Rawls, Dahl y Waldron y como Nino es afecto a cierta versión de la democracia deliberativa ${ }^{104}$, ha admitido (en un texto excepcional que conviene revisar con algún detalle ${ }^{105}$ ) la legitimidad del control judicial de constitucionalidad, pero sólo para ciertos contextos sociales y políticos. De las tres notas del Estado constitucional en sentido estricto (el que corresponde al modelo estadounidense y el europeo de inspiración kelseniana): derechos fundamentales, rigidez constitucional y control judicial, hay que admitir que dos de ellas, la rigidez y el control, son mecanismos contramayoritarios. Sin embargo, dice Bayón, en España hay quienes creen que la democracia constitucional nada tendría de oxímoron, porque la rigidez

\footnotetext{
102 Cf. Ferreres (2010), pp. 376-377.

103 Cf. Ferreres (2010), pp. 377-379.

${ }^{104}$ Si bien combatiendo la tesis de su justificación epistémica: cf. BAYÓN (2009), pp. 189-228.

105 Se trata de BAYÓN (2010), pp. 285-355. Este texto recapitula y mejora aportes anteriores, como los del propio BaYón (2003), pp. 211-238, los de Gargarella (1996), prolongado en (1997), pp. 55-70, y el de Laporta (2001), pp. 459-484.
} 
y el control pueden justificarse al mismo tiempo que se asume el valor de la democracia ${ }^{106}$. ¿Cómo?

El primer argumento es el de que la democracia no es el puro mecanismo formal de la regla mayoritaria, sino un proceso lleno de requisitos sustanciales que han de limitar a la mayoría, como el sufragio libre y universal y todos aquellos derechos que ayudan a la formación y manifestación de decisiones informadas y autónomas ${ }^{107}$. El problema con este argumento es que no ve que la democracia constitucional en realidad conjunta dos ideales igualmente originales, como lo han señalado Rawls y Habermas: el democrático relativo a quién y cómo decide, y el liberal relativo a la limitación del poder. Es verdad que ambos remontan a una misma concepción moral de la persona (la de un 'liberalismo político consecuente'), que es el fundamento común de la capacidad de desarrollar ideas de una vida buena y de una convivencia justa. Pero de todas formas -como lo ha visto tan bien Berlin-puede haber tensiones entre ellos, conflictos que habrá que resolver de alguna manera, democrática o no democrática. He aquí, pues, la paradoja de las precondiciones de la democracia: mientras más se detallen esas precondiciones indispensables para el buen funcionamiento democrático, menos asuntos quedarán entregados a la regla de la mayoría ${ }^{108}$.

El segundo argumento reposa en que una democracia debe respetar a toda costa los derechos básicos de las personas ${ }^{109}$. Los derechos son un coto vedado, un veto, una esfera de lo que es indecidible para la mayoría. El problema es que en sociedades plurales e ideológicamente divididas hay desacuerdos, y no sólo sobre lo bueno sino también sobre lo justo, y tales conflictos deben resol-

106 Cf. BAYÓn (2010), pp. 287-293. Una postura española matizada, pues encara el creciente desprestigio no sólo de la actividad sino de la misma entidad del tribunal constitucional mostrando su posible legitimidad por la mejora de su independencia (a través del cambio en la integración de sus miembros), por una más estricta regulación de sus competencias (en pro de cumplir una mejor labor de garantía) y por una mayor autocontención de parte del mismo (para que no se transforme en una instancia política que perturbe y desfigure la discusión parlamentaria), es la de GARCíA MARTínez (2008), pp. 1-21. Matizada es también la posición de Pereira Menaut, quien, reconociendo los problemas de los tribunales constitucionales, concluye a la luz de sus resultados empíricos que parece más deseable el judicial review anglosajón que los diversos tipos de tribunales kelsenianos, aunque uno y otros sufran tendencialmente el riesgo de la judicialización: (2010), pp. 304-311 y 311-318. Una postura contraria al control judicial de constitucionalidad en España es la de Lora (2009), pp. 127-171.

${ }^{107}$ Cf. BAYÓN (2010), p. 293.

${ }^{108}$ Cf. BAYÓN (2010), pp. 294-299.

109 Cf. BAYÓN (2010), p. 304. 
verse políticamente en algún sentido ${ }^{110}$. Bayón sigue a Waldron: el ideal de los derechos en que se funda la idea de lo indecidible constituye una desarrollada teoría de la justicia, pero sólo una insuficiente teoría de la autoridad. De ahí el carácter incompleto de este segundo argumento ${ }^{111}$. Si hay que resolver las cuestiones de derechos (la constituyente, la de reforma constitucional y la de concreción legislativa de los límites constitucionales), pero sin caer en las aporías que implican las cláusulas de intangibilidad -en efecto, quienes postulan la inmodificabilidad absoluta de los derechos fundamentales, cosa congruente con su carácter indecidible, tienen que enfrentar el hecho de que las constituciones y sus derechos son productos contingentes de diversas decisiones-, entonces habrá que pronunciarse respecto de alguna alternativa de solución. Extraer los derechos de la regla mayoritaria no es la solución, es sólo el descarte de una solución ${ }^{112}$. Parece haber aquí ciertas presuposiciones que convendría explicitar, sugiere Bayón, y que descasan en diferentes interpretaciones de Una teoría de la justicia de Rawls. Según una de ellas, toda forma política de toma de decisiones es un tipo de esquema de justicia procesal imperfecta (y no de justicia puramente procesal ni de justicia procesal perfecta), con lo que el Estado constitucional no sería sino el esquema institucional menos imperfecto de todos, pues "[...] no asegura, sino que meramente hace probable, en mayor o menor medida, la corrección del resultado" 113 . Bayón piensa que a Rawls puede entendérselo aun de otra manera, según la cual un procedimiento político de decisión no ha de juzgarse sólo por su valor instrumental, sino también por su valor intrínseco, debiendo pues efectuarse en cada contexto un balance entre el uno (el valor de los resultados) y el otro (el valor del procedimiento mismo) ${ }^{114}$.

110 "El trazado de la 'esfera de lo indecidible' no es ni puede ser un asunto extrapolítico, sino algo que, de un modo u otro, tiene que hacerse precisamente a través de la política": BAYÓN (2010), p. 306.

${ }^{111}$ Cf. BAYÓN (2010), pp. 306-307 y 312.

112 “[...] Es imposible que los derechos estén sustraídos 'a cualquier poder de decisión', así que el constitucionalismo no es más que un diseño institucional que los encomienda a poderes de decisión distintos del de la mayoría (como mayorías reforzadas u órganos jurisdiccionales)": BAYÓN (2010), p. 312.

113 Cf. BAYÓN (2010), p. 314.

114 "[La más apropiada forma institucional sería...] aquella en la que contamos con criterios independientes del procedimiento para evaluar los resultados de éste, pero contamos, además, con criterios para evaluar el procedimiento mismo que son independientes del valor de los resultados que es probable que produzca. Dicho de otro modo: no importa sólo qué es probable que se decida, sino también cómo se decide [...] Y en ese caso, incluso si fuese cierto que los procedimientos de decisión específicos del Estado constitucional son los que con mayor probabilidad conducirían a resultados que respeten los derechos, con ello aún no estaría zanjada la cuestión de su justificación: porque ese hipotético mayor 
El tercer argumento del constitucionalismo judicial es el del temor a la tiranía de la mayoría. Bayón responde sucintamente: que la mayoría puede ser abusiva, es indiscutible, pero que tienda sistemáticamente a serlo, ya es discutible. También una minoría puede actuar abusivamente, por ej. con el poder de veto que le otorga de facto una regla de supermayoría. Ni la mayoría parlamentaria ni el juez constitucional, ni los momentos constituyentes ni los de la política ordinaria, están en una mejor posición institucional para la protección de los derechos. Por ello no parece posible otorgar in abstracto mayor valor instrumental a un procedimiento decisorio constitucional que incluya dispositivos contramayoritarios que a uno democrático basada en la regla de la mayoría, ni viceversa. El mayor valor instrumental de uno u otro tendrá que decidirse contextualizadamente ${ }^{115}$.

Así, Bayón termina suscribiendo la tesis de la dependencia contextual: el balance del valor intrínseco y del instrumental de un diseño institucional no se puede hacer en general, sino en cada caso, de manera que en diferentes contextos pueden justificarse diferentes procedimientos de decisión ${ }^{116}$. Esto es lo que lo separa de las tesis de Waldron (quien piensa que esta es una inaceptable forma de consecuencialismo de los derechos, contra la cual, como vimos, defiende la idea de que la participación política es 'el derecho de los derechos' ${ }^{117}$ ), de Elster (quien sostiene, como vimos al comienzo, que el constitucionalismo puede y tiene que justificarse por apelación a la noción analógica de precompromiso ${ }^{118}$ ) y de Dworkin (quien sostiene, como acabamos de ver, que para la valoración de un sistema político basta con la virtualidad instrumental -la probabilidad de producir resultados justos- del diseño institucional, sin que deba incluirse además el pretendido valor intrínseco de la igualdad política ínsita en la regla de mayoría ${ }^{119}$ ). En cambio, dice Bayón, es preferible un planteamiento rawlsiano, el cual viene a decir que la participación política tiene valor intrínseco, que por ello cualquier procedimiento contramayoritario es prima facie disvalioso y que por ende la

\footnotetext{
valor instrumental debería contrapesarse todavía con el desvalor intrínseco de sus rasgos contramayoritarios": BAYÓN (2010), pp. 315-316.

115 Cf. BAYÓN (2010), pp. 317, 320-324 y 326-327.

116 Cf. BAYÓN (2010), p. 327.

117 Cf. BAYÓN (2010), pp. 340-344.

${ }^{118}$ Cf. BAYÓN (2010), pp. 332-339.

119 Cf. BAYÓN (2010), pp. 344-351.
} 
justicia constitucional requeriría una especial justificación, una que asegure que por su mayor valor instrumental queda compensado su falta de valor intrínseco ${ }^{120}$. Este planteo tiene la ventaja de corregir el error frecuente de ver en el constitucionalismo una forma de proteger los derechos frente a las mayorías, cuando lo que de veras intenta el constitucionalismo es resolver un conflicto de derechos, el que hay entre la igualdad política o derecho de autogobierno y todos los otros derechos que protegen la autonomía individual ${ }^{121}$.

Ahora bien: entre la democracia pura (la supremacía parlamentaria del casi inexistente modelo de Westminster) y la democracia constitucional (el constitucionalismo fuerte en el que la mayoría está limitada por la rigidez constitucional y el control judicial) hay una tercera alternativa: la de un 'constitucionalismo débil' al estilo del Reino Unido, Canadá o Nueva Zelanda, el cual, dependiendo del contexto social y político, puede llegar a reservar la última decisión a una mayoría parlamentaria ordinaria ${ }^{122}$. ¿Con cuánta frecuencia se presentan estas circunstancias? Según Bayón, cada vez que haya comunidades donde no deba temerse que la mayoría abuse de las minorías lesionando tales o cuales derechos. Si tal no fuera el caso, podrían justificarse distintas fórmulas de constitucionalismo fuerte con mecanismos contramayoritarios. Pero si el procedimiento democrático tuviese al menos el mismo valor instrumental que el procedimiento constitucionalista, entonces el mayor valor intrínseco de aquél debería inclinar la balanza en su favor. Sin que ello obste a posibles diálogos institucionales - por ej. al modo canadiense de la notwithstanding clause- que aumenten la calidad deliberativa de las tomas de decisión, de manera que en los desacuerdos entre parlamentarios y jueces respecto de la concreción de derechos abstractamente formulados por la constitución los legisladores tengan la última palabra, pero no sin considerar explícitamente las razones contrarias argumentadas judicialmente ${ }^{123}$.

\footnotetext{
${ }^{120}$ Cf. BAYÓN (2010), p. 331; vid. pp. 327-331, 340 y 344. Bayón llega a elaborar esta suerte de regla: "aunque el conflicto entre el valor intrínseco y el valor instrumental de un procedimiento es siempre posible, las circunstancias sociales en las que el procedimiento mayoritario realiza en mayor medida su valor intrínseco tienden a coincidir con aquellas en las que menos reticencias hay que tener en relación con su valor instrumental, con aquellas, en suma, en que son más escasas las razones para presuponer que, en comparación con él, desplegará sistemáticamente un mayor valor instrumental un procedimiento que incorpore restricciones contramayoritarias": BAYÓN (2010), p. 354.

${ }^{121}$ Cf. BAYÓN (2010), pp. 331-332.

${ }^{122}$ Cf. BAYÓN (2010), p. 352 n. 172.

${ }^{123}$ Cf. BAYÓN (2010), pp. 354-355 n. 176.
} 


\section{Problemas del CONSTITUCIONALISMO CHILENO}

21. En Chile la discusión sobre estas cuestiones no sólo ha sido dogmáticamente incipiente, sino además políticamente inofensiva. No hay aquí una jurisdicción constitucional que sobresalga por sus argumentaciones, así como tampoco es común una dogmática constitucional conceptualmente sofisticada y que aborde sin complejos las 'cuestiones difíciles': en efecto, entre nosotros parece escasear la reflexión constitucionalista sobre los quiebres políticos chilenos, los regímenes de fuerza (sobre todo el último de ellos, el de Pinochet), la casi completa ausencia de momentos democráticamente constituyentes en la historia republicana de Chile y la posición institucional de la jurisdicción constitucional surgida hace ya cuatro décadas en el entramado del Estado democrático de derecho. Todo esto quizá explique la magra y usualmente eufemística discusión chilena sobre las cuestiones que plantea a la democracia el constitucionalismo fuerte o judicial, según la cual casi parece no haber problema alguno que tocar a propósito de las constituciones rígidas, con revisión judicial y derechos fundamentales. Ha ocurrido tradicionalmente en Chile como ocurrió por mucho tiempo en España: la relación entre constitucionalismo y democracia pareció natural, casi se diría simple. Según Silva Bascuñán, por ej., el TC tiene como misión preservar el Estado de derecho, de manera tal que "la suerte del sistema de gobierno democrático definido en la Carta ha quedado en alto grado en sus manos" 124 . Cea, otro ej., saluda la constitucionalización del derecho, entendiendo que las constituciones tienen primacía jurídica sobre la ley y constituyen un orden de valores, y diciendo -contra los positivistas- que el juez constitucional no es sólo legislador negativo o árbitro de la parte orgánica de la constitución sino -contra los 'jacobinos' partidarios de la soberanía parlamentaria irrestricta- que es también garante de su parte dogmática y por ende contralor del legislador y defensor de los derechos fundamentales ${ }^{125}$. Para Nogueira, en fin, es justificable la jurisdicción constitucional no en Estados autocráticos sino precisamente y sólo en Estados democráticos de derecho que se caracterizan por proteger los derechos de los gobernados ${ }^{126}$.

Con todo, hay recientes motivos de esperanza. Ya se advierten algunas posturas matizadas sobre estos asuntos, en las cuales además aumenta paula-

124 Silva Bascuñán (1993), p. 489, vid. pp. 485-489.

${ }^{125}$ Cf. Cea (2001), pp. 107-110 y 112-113.

126 Cf. Nogueira (1993), p. 438. 
tinamente el recurso a los debates comparados en torno a la justicia constitucional y la dificultad contramayoritaria. Con este trasfondo presente, hay quienes suscriben la objeción democrática al $\mathrm{TC}^{127}$, mientras en el bando opuesto aparecen otros que o bien defienden la necesidad de este tribunal y el valor procesal, argumentativo y aun político que de hecho ha tenido su práctica $^{128}$, o bien celebran el carácter procesalmente avanzado de la práctica constitucional chilena pero lamentando su mal nivel argumentativo -sobre todo por el entreveramiento, en lo que toca a la resolución de los problemas constitucionales, de la corte de casación y tribunales de instancia con el TC ${ }^{129}$. En medio se hallan los que perciben las dificultades de la institución sin pronunciarse nítidamente sobre su legitimidad ${ }^{130}$, algunos de los cuales critican en todo caso la jurisprudencia ponderativa de valores que ha emprendido el TC por errática, activista y expansiva ${ }^{131}$. Dos ejemplos ilustrarán los mayores matices que suele emplear la dogmática constitucionalista reciente.

22. Atria es, según creo, quien primero y más enérgicamente ha emprendido la crítica democrática de la justicia constitucional, siguiendo (al menos en parte) la estela de Dahl y Waldron. Así ha formulado la objeción democrática al mismo: si en cualquier régimen político alguien debe tener la última palabra respecto del diseño institucional y la distribución del poder y en una democracia tal supremacía es detentada por un órgano representativo o de generación popular como el parlamento, entonces la justicia constitucional no puede tener poder sobre el legislador. La usual respuesta de los defensores chilenos del TC reza del siguiente modo: en una democracia es característico que se protejan los derechos de las minorías mediante un catálogo constitucional de

\footnotetext{
${ }^{127}$ Es el caso de F. Atria, como veremos, de E. Aldunate sólo parcialmente (en la medida en que concuerda con Atria, si no en la falta de legitimidad democrática de la justicia constitucional -el asunto parece abierto-, sí en cuanto a que el TC indiscutiblemente requeriría de una dogmática más desarrollada que la que hay y tendría que desarrollar argumentaciones más sofisticadas que las que ha venido llevando a cabo): Aldunate (2009a), y (2009b), esp. pp. 476-478, y últimamente de MaC-Clure, quien sigue fielmente el razonamiento de Atria: (2011), pp. 169-275.

128 P. Zapata, como veremos.

129 Cf. Peña (1999), pp. 155-156 y 198. Atria ha reformulado así una de las afirmaciones de Peña: "nuestra práctica constitucional es procesalmente avanzada porque es argumentativamente arcaica": (2000), p. 389.

130 Cf. Cazor (2003), pp. 39-62, y Gómez (2005), pp. 651-684.

131 Cf. por todos Núñez (2004), 115-136, y (2010), 523-541, Accatino (2006), pp. 17-29, Bordalí (2006), pp. 33-65, y nuevamente Aldunate (2010), pp. 83, 85 y 90-100.
} 
derechos de las personas. Tales derechos son inviolables, y las modificaciones a su respecto requieren de una mayoría parlamentaria calificada para reformar la constitución. Esa supermayoría asegura que no se oprima a las minorías. Por tanto, así como al establecerse una constitución se instaura una limitación real al poder de la mayoría, así también un tribunal constitucional no es sino otro mecanismo protector de las minorías contra la mayoría ${ }^{132}$. La réplica de Atria a esta defensa supone dos tesis. Una, que la teoría de la democracia, o del derecho, o del Estado de derecho, o de los derechos humanos, no exige un control judicial de constitucionalidad. Lo cual implica que dicho control no se justifica apelando al 'verdadero' sentido de las ideas de democracia, derecho, Estado de derecho o derechos humanos, sino por la experiencia y la tradición jurídica y política de cada sociedad. Y la otra tesis: que en Chile esa experiencia y tradición -sobre todo debido al subdesarrollo de la dogmática constitucional chilena y a su irreflexivo carácter ideológico, normalmente de derechas por lo demás- promueven más bien un hondo escepticismo acerca de la conveniencia del control judicial de constitucionalidad ${ }^{133}$. Posteriormente, Atria ha agudizado su objeción al TC volviéndola casi conceptual: en la constitución chilena, como en otras constituciones, dominan los conceptos altamente abstractos (vida, igualdad, libertad, etc.), vale decir, principios a partir de los cuales los jueces del TC juzgan la constitucionalidad de las leyes (y otras normas jurídicas) sin atenerse a reglas previas sino de acuerdo con sus propias concepciones ideológicas, lo que es tanto como decir que las juzgan política, no jurídicamente. Por este motivo el TC sería tribunal sólo por el nombre del órgano, mas no por la función que ejecuta, función que es intrínsecamente política, facciosa: la de una suerte de tercera cámara legislativa que decide y pondera qué significa en concreto cada uno de aquellos conceptos o principios ${ }^{134}$.

\footnotetext{
${ }^{132}$ Cf. Atria (1993), p. 367.

133 AtRia (2000), pp. 347 y 349-350. En este artículo se expone esta tesis: "el extraño caso de la víctima insatisfecha es la historia del sujeto que es golpeado y cuya reacción es entregar al atacante un martillo para que lo golpee con más efectividad. En Chile, los académicos progresistas han tenido un juicio altamente crítico del desempeño de los tribunales en las últimas décadas. No podría ser de otra manera. Pero la paradoja es que al mismo tiempo ellos sostienen que la solución para eso pasa por entregarles más poder. El síndrome de la víctima insatisfecha es extraordinariamente extendido en las pocas páginas que nuestros autores le dedican a este tema": ATRIA (2000), p. 378; vid. en gral. pp. 378-393.

134 "La promesa es atractiva: ese tribunal [el constitucional] sería una instancia en que cada parte concurre sólo con sus argumentos, de modo que ahí dejan de ser relevantes el hecho de que una decisión
} 
23. Un autor que conoce bien estos argumentos de Atria contra la justicia constitucional es Zapata ${ }^{135}$. También conoce y rechaza ciertos argumentos típicamente favorables a la justicia constitucional: ante todo, el de los jueces constitucionales como reserva de sensatez frente a la política democrática; luego, el de que la revisión judicial no está en tensión con la democracia porque los jueces no hacen juicios político-morales sino que sólo aplican decisiones previamente tomadas por los legisladores y administradores ( $₫$ y constituyentes?); en fin, el de que el control judicial no está en tensión con la democracia porque una noción enriquecida de democracia (por ej. "aquel régimen político que garantiza a todas las personas la posibilidad de participar de manera libre e igualitaria en un proceso racional y deliberativo del cual emanarán decisiones

en particular sea beneficiosa para un grupo, o que unos tengan más votos que otros, o que una posición sea más impopular que otra. En ese órgano sólo importaría la coacción racional del mejor argumento. El proceso jurisdiccional efectivamente permite, al menos típicamente, racionalizar de este modo la solución de conflictos, dando entonces a cada parte lo suyo y no lo que convenga al más fuerte. Pero es importante notar que ello es así precisamente porque el juez no hace nada, sino dar a cada uno lo suyo. Esto, sin embargo, es posible sólo cuando se cumplen dos condiciones: que haya reglas que fijen qué es lo suyo de cada uno, y que haya un caso particular en el cual las partes disputen a qué tiene cada uno derecho. Si el juez, junto con (o en vez de) decidir qué es lo suyo de cada uno, ha de decidir cuáles son las reglas conforme a las cuales lo de cada uno debe ser determinado, ya no puede ser juez. Como estas dos condiciones no se cumplen respecto de un órgano que, como el denominado 'tribunal' constitucional, debe decidir sobre la validez de la ley en abstracto, dicho órgano no puede ser un tribunal. Y esto no es una cuestión de palabras, porque lo que significa es que ese órgano no podrá someter los conflictos que le sean sometidos a un estándar de racionalidad más alto que el de los procedimientos políticos que revisa [...] La pretensión de que sólo porque se llama 'tribunal', un órgano que contribuye decisivamente a la formación de la voluntad política se sujetará a un estándar especialmente alto de racionalidad, es fetichista y no descansa en razón alguna. Un famoso profesor norteamericano [Dworkin] ha dicho (refiriéndose a su Corte Suprema) que un tribunal constitucional existe para remover ciertas cuestiones, especialmente importantes, del 'campo de batalla de la política del poder' y llevarlas a un 'foro de los principios'. Pero la propia historia norteamericana (y la chilena, aunque en esto es más breve) ha mostrado que al hacer eso lo único que se logra es arrastrar ese putativo 'foro de los principios' al mismo campo de batalla, como lo sabe cualquiera que conozca el proceso de designación de los miembros de esa Corte norteamericana (o que recuerde el modo en que los nuestros fueron designados). Si las decisiones formadas a través de nuestros procedimientos políticos no son suficientemente racionales, es enteramente fútil crear una tercera cámara para mejorarlas. La cuestión tiene que ser mirar esos procedimientos, y reformarlos de modo que hagan probable una racionalidad mayor. Aunque se denomine 'tribunal constitucional', una tercera cámara no soluciona el problema: sólo lo reproduce": AtRIA (2008). Este argumento ya fue desarrollado con detalle en Atria (2003), esp. 331-332 y 341-344. Atria, como se ve, está aquí muy cerca de Schmitt; vid. por ej. SchmitT y Kelsen (2009), pp. 275-280.

${ }^{135}$ ZAPATA (2008), pp. 19-29. Este autor ha saludado con entusiasmo la crítica de Fallon, Jr. a Waldron: cf. FALLON (2008). 
que, cumpliendo con el marco constitucional y respetando los derechos de las minorías, tengan por objeto el bien común" ${ }^{136}$ ) vuelve indispensable a los jueces constitucionales ${ }^{137}$. ¿Qué dice Zapata por su parte? Cree que en esta discusión se trata de derecho y no sólo de política ${ }^{138}$, que el derecho que aquí está en juego es un derecho justiciable ${ }^{139}$, que la existencia de una justicia constitucional permite una (relativamente mejor) protección de los derechos fundamentales ${ }^{140}$, y que la presencia de una justicia constitucional algo tiene que ver con el pueblo, con la soberanía popular ${ }^{141}$. Siguiendo a Elster, a Ely y a Habermas, Zapata sostiene, en breve, cuatro tesis:

"[...] 1. que la tarea de la aplicación de la ley es distinta a la del legislador; 2. que las reglas que reconocen derechos fundamentales no son solamente expresiones de identidad política ni puros conceptos, sino que son normas jurídicas susceptibles de interpretación relativamente predecible y razonablemente independiente de las concepciones del juez de turno; 3. que la justicia constitucional, pese a acarrear ciertos costos en términos de la extensión del autogobierno, es defendible por sí misma, sin embargo, porque ella sirve fines valiosos, asociados, fundamentalmente, a la seguridad, la libertad y la igual consideración, y 4. la legitimidad de un sistema de justicia constitucional depende de que éste haya sido adoptado, o aceptado, por libre decisión del pueblo y del hecho de que su diseño y su ejercicio respeten, en la mayor medida posible, los espacios de la deliberación política" ${ }^{142}$.

136 Zapata (2008), p. 35.

137 Cf. Zapata (2008), pp. 30-37.

138 Zapata (2008), pp. 38-45. Dice en favor de una aplicación relativamente autónoma del derecho: "la existencia de una dogmática jurídica desarrollada y la operación de incentivos constitucionales adecuados": p. 40.

139 Zapata (2008), pp. 45-48. Y es que, dice, en una constitución no hay sólo normas generales principalmente declarativas, sino también normas concretas, instrumentales y esencialmente reguladoras.

${ }^{140}$ ZAPATA (2008), pp. 49-62. Zapata menciona la posición favorable de Cea a la justicia constitucional, y la de Waldron, para el cual la justicia constitucional, en el mejor de los casos, como muleta transitoria para democracias enfermas.

${ }^{141}$ ZaPATA (2008), pp. 62-72.

${ }^{142}$ ZAPATA (2008), p. 38. Este autor suscribe una postura favorable a la autocontención de la jurisdicción constitucional por deferencia al legislador democrático como la de KRAMER (2012), crítico por lo demás de las tesis de Posner que -veíamos al comenzar-acaban de invocar ministros del TC. 


\section{TAREAS PARA EL CONSTITUCIONALISMO CHILENO}

24. Si quisiera dejar de ser inocuo, el constitucionalismo chileno debería ante todo abandonar su ingenuidad ideológica y esa su manera a veces autista de razonar, enfrentando las cuestiones planteadas en estas páginas no como términos de un saber sui generis ni esencialmente particular o local, sino al modo de problemas que hay que encarar con una actitud cognoscitiva que pretende que sus afirmaciones sean intrínsecamente verificadoras y tendencialmente universales $^{143}$. Solamente así podrá salvar y cultivar los matices que últimamente ha exhibido. Y así, también, podrá aprender de las formas de proceder de otras dogmáticas y teorías políticas y constitucionales, para enseguida estar en condiciones de debatir con ellas y ponerse a elaborar por sí mismo construcciones conceptuales e institucionales que encaren la relación de la democracia con el constitucionalismo. Veamos ambas cosas para terminar.

25. El aprendizaje dogmático implicaría una mayor conciencia de los graves daños causados por "la violenta separación de lo 'exclusivamente jurídico' y lo 'exclusivamente histórico'" 144 y el desarrollo, como se ve en Italia, de una reflexión histórica sobre las peculiaridades del Estado constitucional y democrático. Esta reflexión tiene que ser llevado a cabo comparada y ampliamente, no sólo centrándose en sus habituales ejemplares norteamericanos y europeos, sino también en las peculiaridades que aquel Estado ha tenido en América latina y Chile ${ }^{145}$. Es algo que, entre otras cosas, obligaría a considerar unos fenómenos intensamente estudiados en estas últimas décadas y respecto de los cuales cabría interrogar a Zagrebelsky y Ferrajoli: la (¿deseable?) declinación de la ley y la (¿deseable?) constitucionalización del derecho a ella ligada. La apología de dicha constitucionalización, por cierto, envuelve una ambición algo desmesurada. Y es que incluye no sólo el deseo de reconfigurar las competencias estatales para que se funcionalice de mejor manera el ideal de una democracia deliberativa, sino también la pretensión de una nueva (mejor: el retorno a una antigua) idea del derecho y del estudio del mismo: no la de una scientia, sino la de una prudentia iuris. Por lo primero, en todo caso, habría que volver a plantearse si en una democracia bien entendida y diseñada ha de

${ }^{143} \mathrm{Al}$ respecto, aunque sin referirse solamente al constitucionalismo, cf. BERNASCONI (2007), pp. 9-37.

${ }^{144}$ SchmitT (2001), p. 138.

145 Para Chile, cf. especialmente Cristi y Ruiz Tagle (2006), y Cristi (2011). 
haber espacio (y si sí, bajo qué límites y condiciones) para unos jueces que defiendan la constitución sin incurrir en un activismo que invada el terreno del legislador y la dialéctica ciudadana.

Una dogmática situada a la altura de los tiempos también tendría que asumir, como en la órbita germana, un mayor rigor y una acusada sistematicidad. Estos rasgos, veíamos, felizmente ya se empiezan a apreciar en algunos textos chilenos. Entonces, incluso si se admitiera tanto la legitimidad cuanto la necesidad de una justicia constitucional concentrada, como creen Habermas y Alexy, habría que justificar limpiamente cuál es esa su naturaleza no sólo política sino que política y peculiarmente jurídica (la de una representación argumentativa de los ciudadanos) ${ }^{146}$, establecer argumentadamente sus límites (nuevamente una teoría de los márgenes de acción del legislador) y precisar en qué radicaría la mayor racionalidad que ella -en comparación con el proceso democráticopuede aportar. Esto último supondría, claro, abordar si el razonamiento de los jueces constitucionales no es en el fondo de naturaleza arbitraria, y si su ejercicio consiste no en una subsunción sino en una ponderación de principios constitucionales. Si la ponderación no es subsuntiva o si es un paso previo a la subsunción o incluso si es una marca de toda norma -sea regla o principio, en el entendido de que esta distinción fuera aún defendible-, si es de todas formas racionalmente realizable y controlable, y si posee una estructura imparcial que diverge de aquélla caracteriza al debate parlamentario de diferentes y parciales concepciones políticas: todo ello está en juego a este respecto y tiene que ser encarado con argumentos estrictos ${ }^{147}$.

Además, debería procurarse un mejor análisis de los argumentos de filosofía política y teoría constitucional favorables y contrarios al judicial review, siguiendo en esto los derroteros de la teoría anglosajona y, a su zaga, de la iberoamericana más actual. El nivel que en esta discusión se ha alcanzado es alto, como lo han mostrado los sofisticados ejercicios de Dahl y Rawls, Dworkin y Waldron, Nino, Ferreres y Bayón. Así, pues, convendría detenerse, una vez más,

\footnotetext{
146 Sobre la noción de representación argumentativa, vid. Oliver-Lalana (2011), esp. 168-175. S. Breyer coincide con la distinción entre esta representación argumentativa y la política del parlamento; vid. BREYER (1999), pp. 49-66, y (2000), p. 141.

147 Sobre el carácter racional que tendría la ponderación según Alexy, cf. a favor: Bernal Pulido (2003), pp. 225-238, (2006), pp. 51-75, y (2007), esp. pp. 296-298 y 316-322; y en contra: GARCía AmADO (2007a), pp. 237-264, y sobre todo (2007b), pp. 249-331, así como -siguiendo en general a García Amado- Aldunate (2011), pp. 143-153.
} 
en la pregunta por la legitimidad de las constituciones (why a nation that rests legality on the consent of the governed would choose to constitute its political life in terms of commitments to an original agreement deliberately structured so as to be difficult to change ${ }^{148}$ ), vale decir, de la justificación de que la democracia sea precisamente liberal o constitucional, sea pues un Estado constitucional de derecho. Previamente, incluso, tendría que debatirse acerca de la naturaleza constitucional y en torno al vínculo que tales textos establecen entre el autogobierno y la limitación del poder: ¿las constituciones han de zanjar las reglas del juego político decantándose por alguna concepción en particular?, ¿ ¡ deben más bien condicionar y/o limitar ese proceso político solamente desde la perspectiva del autogobierno y por tanto dejando abiertas las puertas para la libre polémica partisana?, ¿son, pues, en algún sentido precompromisos -como veíamos al principio- de la comunidad política?, y, sea de ello lo que fuere, ¿`cómo se articularán constitucionalmente unas instituciones que hagan justicia a la igualdad política y que a la vez permitan controlar y balancear el ejercicio de la autoridad?, ¿acaso entregando las necesarias limitaciones del poder al criterio pretendidamente neutral de unos jueces?

26. Lo anterior permite tomar parte en las discusiones contemporáneas, mostrando in concreto cómo es que el constitucionalismo ha de producir, en Chile como en cualquier otro lugar, argumentos verificables o falsificables y tendencialmente universales. En particular, creo, este aggiornamento dogmático y teórico debería ejecutarse mediante investigaciones normativas y semánticas y aventurando diseños institucionales que afinen en sociedades como las nuestras los ideales de la deliberación democrática.

Por una parte, el constitucionalismo chileno haría bien en plantearse y tratar con morosidad -como han hecho otras dogmáticas- el alcance interpretativo que tiene el que los constitucionales sean unos conceptos esencialmente controvertidos y unos acuerdos incompletamente teorizados ${ }^{149}$. Lo que, como hemos visto, obliga a decidir con argumentos precisos si estos conceptos convencionales están en condiciones de legitimar a la justicia constitucional y, en caso de que sí lo estuvieran, hasta qué punto y bajo qué formas. Y es que de no poder prescindir las constituciones de tales conceptos, principios y/o valores esen-

\footnotetext{
${ }^{148}$ Es la famosa cuestión que plantea L. Tribe desde 1978 en su American Constitutional Law, aquí citado a partir de PÁramo (2002), p. 447.

149 Sobre esto, vid. el clásico Gallie (1956), pp. 167-198, una suerte de prolongación del mismo en Iglesias (2000), pp. 77-104, y Aguiló (2001), pp. 429-457, y (2010), pp. 247-263.
} 
cialmente indeterminados o abiertos, habrá que tomar postura ante la cuestión de si se los debe entregar sin restricciones a la libre y autónoma determinación política por medio de la polémica entre concepciones ideológicas y facciosas, o si antes de la lucha política -o incluso mediando la misma- éstos habrían de encomendarse a un encuadramiento judicial, a una supradeterminación jurídica que los pondere racionalmente mediante un juicio de proporcionalidad y que, en todo caso, se desarrolle muy restrictivamente, de manera deferente para con el legislador y por ende con un acusado sentido de la autocontención ${ }^{150}$.

Se diría, además, que este asunto tiene que ser abordado no sólo dando por sentadas las instituciones realmente existentes, sino también con una crítica tematización de tales instituciones, aventurando entonces posibles diseños institucionales que puedan complementar, mejorar o aun reemplazar el mecanismo de la revisión judicial. Convendría, por lo mismo, que el constitucionalismo chileno diera ya unos primeros pasos en esta dirección -cosa que, hasta donde sé, prácticamente no ha sucedido-, y comparara algunos de los diversos arreglos constitucionales y políticos (como el británico, el neozelandés, el canadiense, el israelí, el colombiano) que se han ensayado para terminar con la tensión entre jueces constitucionales y legisladores representativos. $\mathrm{O}$ cuando menos para morigerarla, considerando formas democráticamente satisfactorias de diálogo interorgánico -formas de eso que Bayón denominaba constitucionalismo débil, caracterizado por entregar la última palabra a los parlamentos en caso de conflicto entre estos órganos representativos y los contralores judiciales de constitucionalidad ${ }^{151}$.

Por otra parte, y por especulativo que parezca, convendría volver a incidir en la estructura de lo constitucional. En Chile se suele identificar a las constituciones como el producto característico del constitucionalismo originalmente liberal de la limitación del poder, sin parar mientes en que constituciones son también las que ha generado el constitucionalismo ya democrático que ha incorporado el autogobierno $-\mathrm{y}$ en las que por ende se produce el conflicto entre derechos y regla mayoritaria. No es raro que en la enseñanza y aun en las investigaciones de la doctrina constitucional chilena todavía se pasen por

\footnotetext{
${ }^{150}$ Una argumentación favorable a esta forma judicialmente autolimitada de proceder, en el campo penal, es la que analiza la recensión de Silva Sánchez (2007), pp. 1-6.

${ }^{151}$ Acerca del caso canadiense destacado por Bayón, vid. Kelly y Manfredi (2009). Sobre este y los otros casos mencionados, cf. el panorama que ofrece Linares (2008), quien incluso discute el (sumamente polémico) litigio de reforma estructural promovible por la judicatura constitucional en algunos sistemas jurídicos (cf. pp. 523-531).
} 
alto las dificultades de compaginar institucionalizadamente al liberalismo con la democracia. Es algo que ocurre entre constitucionalistas con un desangelado afecto por los ideales de una república deliberativa (sobre todo por el de igualdad política) ${ }^{152}$, pero que también afecta al constitucionalismo chileno concernido -de alguna manera hay que decirlo- por tales ideales. Véase por ej. esta reciente alusión al constitucionalismo original sobre el telón del fondo del reclamo neoconstitucionalista:

"el constitucionalismo, como fenómeno social, político y jurídico originado a fines del siglo XVIII y primer tercio del siglo XIX, tiene unos contornos bien precisos; se trata, en primera línea, de un movimiento político, con inspiración filosófica ilustrada que, sobre la base del cuestionamiento de los criterios de legitimación tradicional, busca dotar al poder de un fundamento de legitimidad racional, tanto desde el punto de vista de su forma -la ordenación articulada y sistemática de los fundamentos de la organización política en un solo instrumento-, como desde el punto de vista de su origen -una ordenación objeto de una decisión

${ }^{152}$ Que precisamente entre constitucionalistas despunte a veces un anémico compromiso republicano, liberal y democrático no llama, después de todo, la atención, sobre todo a partir del quiebre político y constitucional chileno de 1973, a cuyo posterior proceso constituyente prestaron servicio varios constitucionalistas nacionales. Cosa que contrasta, claro, con las severas prevenciones que oponen también constitucionalistas a un nuevo proceso constituyente -esta vez democrático y republicanorespecto de cuya necesidad últimamente se discute. Vid. por ej. algunas expresiones de Fermandois (2012): "¿qué significa una asamblea constituyente? Significa invocar el poder constituyente originario. Significa desahuciar la operatoria del poder constituyente derivado, aquel mecanismo que hasta 2009 permitió modificar 242 veces la actual Carta, medido por número de artículos enmendados. Significa recurrir a la facultad suprema de la soberanía, aquella que la autoriza para dictar una nueva Constitución despercudida de todos sus límites positivos. No habría quórum, artículo, compromiso, sentencia firme o derecho adquirido que pueda limitar a esta feroz explosión de poder jurídico y fáctico llamado poder constituyente originario [...] En rigor, una asamblea de esta clase despoja a todos los poderes constituidos de sus potestades. Nadie se salva de una reconfiguración global del poder. Todas las atribuciones del Congreso, del Presidente de la República, de la administración del Estado, de los tribunales de justicia, del contralor general, de las municipalidades, etc., quedan trasladadas, vaciadas y concentradas en un grupo de personas investidas de estas atribuciones plenipotenciarias. Ellos refundarán el país; ya no el modelo económico, ni la relación entre el Estado y la persona, sino todo: se trata de reformular los órganos y sus atribuciones, el catálogo de derechos, los principios que rigen al Estado, hasta el nombre del país e incluso -vaya ingenuidad, y ha ocurrido- los límites y fronteras del Estado". En términos parecidos se manifiesta Verdugo (2012): "en estos últimos días, incluso algunos legisladores muy representativos para la opinión pública, parecen haberse percatado, tal vez por primera vez, que se encuentran atrapados en la redes del sistema y, en esta contingencia, adhieren con entusiasmo a la proposición de convocar a una asamblea constituyente. Como tal procedimiento carece de todo asidero en la normativa vigente, de concretarse, ello implicaría un quiebre institucional, con todas la consecuencias que conlleva. Cabe preguntarse: ¿no sería peor el remedio que la enfermedad?”. Las cursivas, en ambos casos, son mías. 
consciente y deliberada del cuerpo político o sus representantes-, así como desde la perspectiva de su contenido -la consagración de un régimen de limitación del poder a través de la sujeción de las autoridades a la constitución y a las leyes-, de la división del poder en distintos poderes separados y de la declaración de los derechos individuales. Dicho de otra manera, el constitucionalismo persigue que los Estados se doten de constituciones, entendidas de la manera señalada. Puede considerarse un verdadero programa político, basado en unos postulados filosófico-políticos y jurídicos, y que permite, a sus adherentes, identificarse nominativamente con la denominación"153.

Decir esto no es incorrecto, por cierto, pero sí que es decir algo muy abstracto: si el neoconstitucionalismo no es una mera renovación -un revival- del constitucionalismo originario, es porque representa una cierta configuración -por vaga que sea- del constitucionalismo ya democrático de las últimas décadas, y una que intenta encarar-mejor o peor- las tensiones entre la tesis democrática del autogobierno y la tesis liberal de los derechos. El mismo texto citado lo insinúa después cuando dice que el neoconstitucionalismo alude a "ciertos fenómenos o prácticas institucionales de los estados constitucionales -en su inicio, europeos- tras la Segunda Guerra Mundial”. Cuando se habla de constituciones, por ello, no se habla sólo de las del constitucionalismo original, sino también de las del constitucionalismo democrático posterior. Si en sus inicios el constitucionalismo era más liberal que democrático, justo con la progresiva democratización del liberalismo apareció un grave problema: y es que la cuestión del origen del poder -la comunidad política que se gobierna- no se coordina naturalmente con la del contenido o ejercicio del mismo -los límites y divisiones del poder y los derechos individuales. Por esta plurivocidad del concepto de constitución es que cabe decir que las constituciones han sido el artefacto paradigmático del constitucionalismo y, conviene repetir, tanto del constitucionalismo originariamente liberal como del posteriormente democrático. Así, si "desde el punto de vista de su origen [la constitución del constitucionalismo es] una ordenación objeto de una decisión consciente y deliberada del cuerpo político o sus representantes", también es cierto -y conviene añadirlo de inmediato- que, tratándose ya de democracias liberales (que se anuncian recién en el siglo XIX y solo toman cuerpo en el XX y el XXI), el cuerpo político es tanto el objeto como el sujeto

153 Aldunate (2010), p. 80. 
del acto constituyente. La comunidad política no es sólo el origen del poder, sino también la materia misma de él y de la decisión constitucional. La soberanía -término en crisis, pero todavía necesario- es la autonomía que cabría predicar de la comunidad política. De ahí que tenga que ser posible imputar tal poder y tal decisión (así como esas decisiones posteriores que son las leyes) a la comunidad, aun cuando su voluntad soberana se exprese en importante medida a través de sus representantes. Las constituciones, entonces, seguirán siendo límites para el poder político, pero lo serán sobre la base de la igualdad política, vale decir, manifestando y operacionalizando con muy concretos contenidos la tensa reunión del principio liberal y el democrático.

Por lo mismo, uno tiene la impresión de que habría que proseguir esta vía: la que sugiere que las constituciones actuales tendrían que entenderse como la apertura de un espacio para que la comunidad política se identifique y así haga posible su propio autogobierno, es decir, deberían considerarse no como unas leyes jerárquicamente superiores que permiten resolver los desacuerdos acerca de nuestros compromisos comunes mediante adjudicaciones judiciales, sino como el establecimiento de un ámbito común donde la especificación de lo que las normas constitucionales implican en cada circunstancia se decide a través del conflicto político y por deliberación ${ }^{154}$. En este sentido, la constitución vendría a ser no tanto un límite cuanto una condición de la práctica política democrática, una serie de conceptos que no quieren adjudicar conflictos políticos sino que pretenden discriminar entre aquellos conflictos que son políticos de aquellos que son "(abierta o solapadamente) militares"155. Suavizando estas afirmaciones, cabría decir que ahora la constitución es entendida no sólo como límite de la política democrática, sino también como condición de la misma. La constitución efectivamente permite e impulsa el proceso político, pero admitiendo, como proponía Dahl, que el poder tiende a corromper, el poder absoluto, a corromper absolutamente, y manteniendo por ende una actitud liberal, escéptica y desconfiada respecto de todo tipo de poder, incluido el poder democrático.

¿Cabe teorizar de mejor manera el que la constitución sea un difícil equilibrio entre el derecho a la igualdad política y el conjunto de los derechos liberales? Probablemente sí. Las dificultades que surgen cuando se trata de

${ }^{154}$ Es lo que ha hecho Atria; cf. (2011), p. 77, y (2007), pp. 64-66.

155 ATRIA (2011), pp. 77-78. 
reunir a la democracia con los derechos son las que han llevado a emplear las ideas de Hayek sobre órdenes espontáneos y creados, sugiriéndose que

"la constitución misma es un orden que no sólo tiene finalidades, sino que las declara al principio. Y la idea que guía ese orden no es la de reemplazar el orden espontáneo por un orden creado, sino construir sobre los intereses y finalidades anticipables de cada uno, con la finalidad de alinear el interés individual y el interés general [...] Dicho de otro modo, no se trata de crear un orden constitucional que imponga a cada agente un deber que debe entonces ser cumplido por ese agente con independencia de sus intereses reales y concretos (es decir: no se trata de un orden creado); se trata, al contrario, de configurar institucionalmente la posición de cada agente de modo que lo que vaya en su interés sea además lo que preserva la estructura del orden. Se trata, en otras palabras, de crear, 'a través de la reflexión y la elección', un orden espontáneo [...] Todo lo que es necesario para mantener la conexión interna entre orden y libertad es que los órdenes bajo los cuales los individuos deben llevar adelante sus planes de vida han de ser tales que no les exijan que, para ser exitosos, abandonen sus finalidades y adopten finalidades que a ellos aparecen ajenas, las del orden"156.

Esto -que las constituciones fundan una comunidad no sustituyendo el orden espontáneo sino más bien con la pretensión de que perseguir el propio interés sea alineable con la promoción del interés general- es interesante, pero nada novedoso. Lo que no distingue Hayek es algo que otros ya sabían, como Smith ${ }^{157}$ y Hegel. Refiriéndose al Estado moderno, en efecto, Hegel decía que no hay por qué pensar que el interés particular sólo sea coordinable con el interés general por la vía de la asfixia de aquél. Al contrario, la idea del Estado en la época moderna (en su mejor versión, claro) se constituye como "la efectiva realidad de la libertad concreta (die Wirklichkeit der konkreten Freiheit)" ${ }^{158}$. Y es que la libertad concreta consiste "en que la singularidad personal y sus particulares intereses (die persönliche Einzelnheit und deren besondere Interessen) tengan completo desarrollo y reconocimiento de su derecho para sí (en el sistema de la familia y de la sociedad civil), como en que se transformen por sí mismos en el interés de lo universal (in das Interesse des Allgemeinen), al que reconozcan con su saber y su voluntad como su propio espíritu sustancial (substantiellen Geist)

156 Atria (2010), pp. 87-89. Del mismo, vid. (2007), pp. 27-34.

157 A quien el mismo Atria cita; vid. (2007), pp. 30-31 y 75.

158 G. W. F. Hegel, Grundlinien der Philosophie des Rechts, $\$ 260$. 
y para el cual sean activos en cuanto que su finalidad última (alsibren Endzweck tätig sind)" 159 . La extrema subjetividad debe ser dejada en libertad, y al mismo tiempo ha de ser retrotraída a la unidad sustancial ${ }^{160}$. Y en la Enzyklopädie de 1830, Hegel agrega que el Estado es un todo (Ganzes) organizado y diferenciado que resulta de particulares virtualidades (in die besondern Wirksamkeiten), y que justamente esta estructuración o articulación (Gegliederung) del poder político estatal es la constitución (Verfassung) ${ }^{161}$.

Las constituciones, pues, serían arreglos institucionales que tratan de favorecer, todo lo imperfectamente que se quiera, alguna coordinación de los intereses particulares con el general, y que no -al menos no necesariamente- se comprometen con la tesis neoliberal de la indeseabilidad e imposibilidad de organizar institucionalmente las cosas de manera que en un orden básicamente espontáneo (no creado ni administrado centralizadamente) sea posible y por lo menos probable tal coordinación.

27. Aún es novedoso en Chile lo que en otros lugares ya es moneda corriente: admitir y enfrentar in modo recto la tensión inevitable que hay entre democracia y constitucionalismo. Una tensión que puede llevar a justificar procedimental y/o sustantivamente la existencia del mecanismo de control judicial de constitucionalidad -en el entendido de que tal órgano sólo funciona de maneras aceptables cuando los jueces actúan restrictiva y contenidamente, mostrando claros compromisos republicanos y democráticos y tanta sofisticación y pluralismo como los que se hallan en la dogmática constitucional de la que surgen y gracias a la cual se nutren-, pero que también podría aconsejar bien el abandono del mismo, bien su acomodación mediante el otorgamiento al representante democrático de la última palabra en la configuración de los derechos fundamentales y en el diseño de las políticas estatales.

Lo que no puede aceptarse, en fin, es que el juez constitucional todavía piense que "[...] en cuanto órgano jurisdiccional, no tiene una política o agenda propia, pues ello sería signo de activismo judicial, sino un deber que cumplir y que es inexcusable: resolver los asuntos que sean sometidos a su conocimiento y asegurar a través del ejercicio de sus competencias la supremacía constitucional" 162 , como si no tuviese sentido todo lo que se ha dicho y escrito

\footnotetext{
159 Hegel, Grundlinien, $\$ 260$.

${ }^{160}$ Cf. Hegel, Grundlinien, $\$ 260$. Cf. el inicio de los Zusätze al $\$ 260$ y al $\$ 270$.

${ }^{161}$ Cf. G. W. F. Hegel, Enzyklopädie der philosophischen Wissenschaften im Grundrisse, $\$ 539$.

${ }^{162}$ Bertelsen (2011), p. 24.
} 
acerca del liberalismo de la Corte Warren, o no se supiese ni discutiera que muchos de los jueces del BVerfGE han sido tradicionalmente acordados por la CDU y la SPD, o fuese exagerado calificar de militantemente pro-life a la lectura que del art. 19 No 1 de la constitución chilena ha realizado el TC. Vale decir, como si discernir el alcance de conceptos esencialmente controvertidos como los constitucionales o -en los términos del TC- sustituir la voluntad del representante o no presumir la constitucionalidad de sus leyes, fuese algo realizable no sólo de modo altamente racional, sino además prescindiendo de toda agenda política. O sea, como si el pacto constitucional que crea y determina a la comunidad política posibilitara lo imposible: el juzgamiento de los desacuerdos políticos por parte de unos profesionales de la aplicación del derecho -unos jueces- insuperablemente racionales y por lo mismo sutilísimamente neutrales.

\section{REFERENCIAS BIBLIOGRÁFICAS}

AcCatino, Daniela (2006), "La interpretación de los derechos fundamentales y la seguridad jurídica. Una mirada a la práctica constitucional chilena”, en A. Bordalí, coord., Justicia constitucional y derechos fundamentales (Stgo. de Chile, Lexis), pp. 17-29.

Aguiló, Josep (2001), "Sobre la constitución del Estado constitucional", en Doxa 24, pp. 429-457.

Aguilo, Josep (2010), "Sobre las contradicciones (tensiones) del constitucionalismo y las concepciones de la constitución”, en Carbonell, M. y García, L., coord., El canon neoconstitucional (Madrid, Trotta), pp. 247-263.

Aldunate, Eduardo (2009a), Jurisprudencia constitucional 2006-2008 (Stgo. de Chile, Legal Publishing).

Aldunate, Eduardo (2009b), "La fuerza normativa de la Constitución y el sistema de fuentes del derecho", en Revista de Derecho. Pontificia Universidad Católica de Valparaiso 32, pp. 443-484.

Aldunate, Eduardo (2010), "Aproximación conceptual y crítica al neoconstitucionalismo", en Revista de Derecho. Universidad Austral de Chile 23/1, pp. 79-102.

Aldunate, Eduardo (2011), "Principios jurídicos y neoconstitucionalismo", en Carbonell, F. et alii, eds., Principios jurídicos. Análisis y crítica (Stgo. de Chile, Abeledo Perrot/Thomson Reuters), pp. 143-153. 
Alexander, Larry, (1998), ed., Constitutionalism. Philosophical Foundations (Cambridge, CUP).

Alexy, Robert (2003a), "Los derechos fundamentales en el Estado constitucional democrático", en M. Carbonell, ed., Neoconstitucionalismo(s) (trad. A. García Figueroa, Madrid, Trotta), pp. 31-47.

Alexy, Robert (2003b), "Derecho constitucional y derecho ordinario-Jurisdicción constitucional y jurisdicción ordinaria", en Tres escritos sobre los derechos fundamentales y la teoría de los principios (trad. C. Bernal Pulido, Bogotá, U. Externado de Colombia), pp. 41-92.

AleXY, Robert (2008), "La fórmula del peso", en La teoría de la argumentación jurídica (trad. M. Atienza e I. Espejo, Madrid, CEPC), pp. 349-374.

AleXy, Robert (2009), "Los principales elementos de mi filosofía del derecho" (trad. D. Oliver-Lalana), en Doxa 32, pp. 67-84.

AleXY, Robert (2010), "La teoría del discurso y los derechos fundamentales", en Menéndez, A. y Eriksen, E., eds., La argumentación y los derechos fundamentales (trad. C. Bernal Pulido, Madrid, CEPC), pp. 29-48.

ATria, Fernando (1993), "El Tribunal Constitucional y la objeción democrática", en Revista Chilena de Derecho 20/2-3, pp. 367-378.

Atria, Fernando (2000), "Revisión judicial: el síndrome de la víctima insatisfecha” en Estudios Públicos 79, pp. 347-402.

Atria, Fernando (2003), "El derecho y la contingencia de lo político", en Doxa 26, pp. 319-345.

Atria, Fernando (2007), Mercado y ciudadanía en la educación (Stgo. de Chile, Flandes Indiano).

Atria, Fernando (2008), "El Tribunal Constitucional como tercera cámara", en La Segunda (09/09/08).

Atria, Fernando (2010), "Socialismo hayekiano", en Estudios Públicos 120, pp. 49-105.

Atria, Fernando (2011), "Lo que importa sobre los principios", en Carbonell, F. et alii, eds., Principios jurídicos. Análisis y crítica (Stgo. de Chile, Abeledo Perrot/Thomson Reuters), pp. 65-90.

BAYÓN, Juan Carlos (2003), "Derechos, democracia y constitución”, en Carbonell, M., ed., Neoconstitucionalismo(s) (Madrid, Trotta), pp. 211-238.

BAYÓN, Juan Carlos (2009), “¿Necesita la república deliberativa una justificación epistémica?”, en Diritto \& questioni pubbliche 9, pp. 189-228. 
BAYÓN, Juan Carlos (2010), "Democracia y derechos: problemas de fundamentación del constitucionalismo", en Carbonell, M. y García, L., coord., El canon neoconstitucional (Madrid, Trotta), pp. 285-355.

Bernal Pulido, Carlos (2003), "Estructura y límites de la ponderación", en Doxa 26, pp. 225-238.

Bernal Pulido, Carlos (2005), "Tribunal constitucional, legislador y principio de proporcionalidad", en Revista española de derecho constitucional 74, pp. 417-443.

Bernal Pulido, Carlos (2006), "La racionalidad de la ponderación”, en Revista Española de Derecho Constitucional 77, pp. 51-75.

Bernal Pulido, Carlos (2007), "Refutación y defensa del neoconstitucionalismo", en M. Carbonell, ed., Teoría del neoconstitucionalismo (Madrid, Trotta), pp. 289-325.

BernAsCONI, Andrés (2007), "El carácter científico de la dogmática jurídica", en Revista de Derecho. Universidad Austral de Chile 20/1, pp. 9-37.

Bertelsen, Raúl (2011), "Cuenta pública del Presidente del Tribunal Constitucional 2011", disponible en http://www.tribunalconstitucional.cl/wp/ wp-content/uploads/Cuenta-2011.pdf.

Blanco Valdés, Roberto (2010a), El valor de la constitución. Separación de poderes, supremacía de la ley y control de constitucionalidad en los orígenes del Estado liberal (Madrid, Alianza).

Blanco Valdés, Roberto (2010b), La construcción de la libertad. Apuntes para una historia del constitucionalismo europeo (Madrid, Alianza).

BÖCKENFÖRDE, Ernst (2000), Estudios sobre el Estado de derecho y la democracia (trad. R. de Agapito, Madrid, Trotta).

Bordalí, Andrés (2006), "La tutela de los derechos fundamentales bajo un sistema dual de justicia constitucional", en Bordalí, A., coord., Justicia constitucional y derechos fundamentales (Stgo. de Chile, Lexis), pp. 33-65.

BREYER, Stephen (1999), "Revisión judicial: la perspectiva de un juez" (trad. F. Atria), en Estudios Públicos 75, pp. 49-66.

Breyer, Stephen (2000), "Entrevista al juez Stephen Breyer, juez de la Corte Suprema de EE.UU.” (trads. J. Klein y R. Correa), en Estudios Públicos 80, pp. 119-147.

Cazor, Kamel (2003), "El fenómeno de la constitucionalización del derecho: cuestiones de mera legalidad, de trascendencia constitucional y derechos 
fundamentales", en J. C. Ferrada, coord., La constitucionalización del derecho chileno (Stgo. de Chile, Jurídica de Chile), pp. 39-62.

CEA, José Luis (2001), "La justicia constitucional y el tribunal de la Constitución en Chile", en Revista de Derecho 12, pp. 107-118.

Cristi, Renato y Ruiz Tagle, Pablo (2006), La república en Chile. Teoría y práctica del constitucionalismo republicano (Stgo. de Chile, LOM).

Cristi, Renato (2011), El pensamiento politico de Jaime Guzmán. Una biografía intelectual (Stgo. de Chile, LOM, 2a ed.).

DAHL, Robert (1957), "Decision-Making in a Democracy: The Supreme Court as a National Policy-Maker", en Journal of Public Law 6, pp. 279-295.

DAHL, Robert (1991), La democracia y sus críticos (trad. L. Wolfson, B. Aires, Ariel).

Dreier, Ralf (1991), "Konstitutionalismus und Legalismus. Zwei Arten juristischen Denkens im demokratischen Verfassungsstaat", en Archiv für Rechts- und Sozialphilosophie 40, pp. 85-97.

Dworkin, Ronald (1996), Freedom's Law. The Moral Reading of the American Constitution (Oxford, OUP).

DwOrKIn, Ronald (2007a), "Rawls y el derecho", en La justicia con toga (trad. M. Iglesias e Í. Ortiz, Madrid, M. Pons), pp. 263-284.

DwOrKIN, Ronald (2007b), "Originalismo y fidelidad", en La justicia con toga (trad. M. Iglesias e Í. Ortiz, Madrid, M. Pons), en Justicia, pp. 135-157.

Dworkin, Ronald (2007c), "En alabanza de la teoría", en La justicia con toga (trad. M. Iglesias e Í. Ortiz, Madrid, M. Pons), pp. 63-88.

Dworkin, Ronald (2008), La democracia posible. Principios para un nuevo debate político (trad. E. Weikert, Barcelona, Paidós).

DwORKIN, Ronald (2010), "Igualdad, democracia y constitución: nosotros, el pueblo, en los tribunales”, en Carbonell, M. y García, L., eds., El canon neoconstitucional (Madrid, Trotta), pp. 117-149.

ELSTER, Jon (2002), Ulises desatado. Estudios sobre racionalidad, precompromiso $y$ restricciones (trad. J. Mundó, Barcelona, Gedisa).

FALlON, Jr., Richard (2008), "The core of an uneasy case for judicial review", en Harvard Law Review 121/7, pp. 1693-1736.

Fermandois, Arturo (2012), "Qué significa una asamblea constituyente", en La Tercera (02/09/2012), disponible en http://www.latercera.com/noticia/ opinion/ideas-y-debates/2012/09/895-481171-9-que-significa-una-asambleaconstituyente.shtml. 
Ferrajoli, Luigi (2011), Principia iuris. Teoría del derecho y de la democracia Vol. 1: Teoría del derecho (trad. J. C. Bayón et alii, Madrid, Trotta).

Ferreres, Víctor (2002), "Una defensa de la rigidez constitucional”, en Navarro, P. y Redondo, M. C., comps., La relevancia del derecho. Ensayos de filosofía jurídica, moral y politica (Barcelona, Gedisa), pp. 227-245.

Ferreres, Víctor (2007), Justicia constitucional y democracia (Madrid, CEPC).

Ferreres, Víctor (2010), "El control judicial de la constitucionalidad de la ley. El problema de su legitimidad democrática”, en Carbonell, M. y García, L., coord., El canon neoconstitucional (Madrid, Trotta), pp. 356-380.

Ferreres, Víctor (2011), Una defensa del modelo europeo de control de constitucionalidad (Madrid/Barcelona/B. Aires, M. Pons).

Gallie, Walter Bryce (1956), "Essentially contested concepts", en Meeting of the Aristotelian Society 56, pp. 167-198.

García Amado, Juan Antonio (2007a), "Derechos y pretextos. Elementos de crítica del neoconstitucionalismo", en Carbonell, M., ed., Teoría del neoconstitucionalismo (Madrid, Trotta), pp. 237-264.

García Amado, Juan Antonio (2007b), "El juicio de ponderación y sus partes. Una crítica”, en García, R., ed., Derechos sociales y ponderación (Madrid, Fundación Coloquio jurídico europeo), pp. 249-331.

García Martínez, María Asunción (2008), "Quis custodiet custodes? El Tribunal Constitucional y la garantía del orden constitucional”, en InDret 4, pp. 1-21.

Gargarella, Roberto (1996), La justicia frente al gobierno. Sobre el carácter contramayoritario del poder judicial (Barcelona, Ariel).

Gargarella, Roberto (1997), "La dificultad de defender el control judicial de las leyes", en Isonomía 6, pp. 55-70.

GaRZÓn VAldÉs, Ernesto (1989), "Representación y democracia", en Doxa 6, pp. 143-164.

Ghosh, Eric (2010), "Deliberative Democracy and the Countermajoritarian Difficulty: Considering Constitutional Juries", en Oxford Journal of Legal Studies 30/2, pp. 327-359.

GÓmEZ, Gastón (2005), "La reforma constitucional a la jurisdicción constitucional. El nuevo Tribunal Constitucional chileno”, en Zúñiga, F., coord., Reforma constitucional (Stgo. de Chile, LexisNexis), pp. 651-684. 
GonZÁlez, Antonio (1997), Estructuras de la praxis. Ensayo de filosofía primera (Madrid, Trotta).

Häberle, Peter (2002), Constitución como cultura (trad. A. M. Montoya, Bogotá, Universidad Externado de Colombia).

HäBERLE, Peter (2004), "La jurisdicción constitucional en la fase actual de desarrollo del Estado constitucional" (trad. J. Brage), en Teoría y realidad constitucional 14, pp. 153-176.

Habermas, Jürgen (1998), Facticidad y validez. Sobre el derecho y el Estado democrático de derecho en términos de teoría del discurso (trad. M. Jiménez Redondo, Madrid, Trotta).

Holmes, Stephen (1999), "El precompromiso y la paradoja de la democracia", en Elster, J. y Slagstad, R., eds., Constitucionalismo y democracia (trad. M. Utrilla, México, FCE), pp. 217-262.

Iglesias, Marisa (2000), "Los conceptos esencialmente controvertidos en la interpretación constitucional”, en Doxa 23, pp. 77-104.

Kelly, James y Manfredi, Christopher (2009), eds., Contested Constitutionalism. Reflections on the Canadian Charter of Rights and Freedoms (Vancouver, UBC Press).

KRAMER, Larry (2012), "Judicial Supremacy and the End of Judicial Restraint", en California Law Review 100/3, pp. 621-634.

LAPORTA, Francisco (2001), "El ámbito de la constitución", en Doxa 24, pp. 459484.

LinARES, Sebastián (2008), "El diálogo democrático entre las cortes y las instituciones representativas", en Revista mexicana de sociología 70/3, pp. 487539.

LORA, Pablo de (2009), “Aborto, democracia y justicia constitucional (a propósito de "El derecho constitucional al aborto en los Estados Unidos: una introducción' de Ian Shapiro)", en Shapiro, I., Lora, P. de y Tomás-Valiente, C., La Suprema Corte de Estados Unidos y el aborto (Madrid, Fundación Coloquio Jurídico Europeo), pp. 127-171.

Mac-Clure, Lucas (2011), "Tribunal Constitucional y los derechos: la discusión pendiente", en Sierra, L. y Mac-Clure, L., Frente a las mayorías: leyes supramayoritarias y Tribunal Constitucional en Chile (Stgo. de Chile, PNUD), pp. 169-275.

Martí, José Luis (2006), La república deliberativa. Una teoría de la democracia (Madrid/Barcelona, Marcial Pons). 
Nino, Carlos (1997), La constitución de la democracia deliberativa (trad. R. Saba, Barcelona, Gedisa).

Nogueira, Humberto (1993), "La justicia constitucional como defensa de la Constitución”, en Revista Chilena de Derecho 20/2-3, pp. 417-439.

NúÑEZ, Manuel (2004), "Una introducción al constitucionalismo postmoderno y al pluralismo constitucional", en Revista chilena de derecho 31/1, 115-136.

NúÑEZ, Manuel (2010), "El neoconstitucionalismo y el recurso a los valores en la jurisprudencia del Tribunal Constitucional chileno", en Revista de Derecho. Universidad Católica de Valparaíso 34/1, pp. 523-541.

Oliver-Lalana, Daniel (2011), "Representación argumentativa y legitimidad democrática en las decisiones judiciales", en Clérico, L., Sieckmann, J.-R. y Oliver-Lalana, D., coords., Derechos fundamentales, principios y argumentación. Estudios sobre la teoría jurídica de Robert Alexy (Granada, Comares), pp. 147-175.

PÁramo, Juan Ramón de (2002), "Compromisos, grilletes de cadena y nudos corredizos”, en Zapatero, V., ed., Horizontes de la filosofia del derecho. Homenaje a Luis García San Miguel (Universidad Alcalá de Henares), pp. 443-454.

Peña, Carlos (1999), Práctica constitucional y derechos fundamentales (Stgo. de Chile, Corporación Nacional de Reparación y Reconciliación).

Pereira Menaut, Antonio-Carlos (2010), Lecciones de Teoría Constitucional (Madrid, Colex).

Posner, Richard (2012), "The rise and fall of judicial self-restraint", en California Law Review 100/3, pp. 519-556.

RaWLs, John (2006a), Teoría de la justicia (trad. M. D. González, FCE, México).

RaWLS, John (2006b), Liberalismo politico (trad. S. Madero, México, FCE).

RaWLs, John (2009), Lecciones sobre la historia de la filosofía politica (trad. A. Santos, B. Aires, Paidós).

Schmitt, Carl (2001), "Conceptos y posiciones en la guerra con WeimarGinebra-Versalles, 1923-1939”, en Carl Schmitt, teólogo de la politica (trad. A. Scherp, México, FCE), pp. 65-166.

Schmitt, Carl y Kelsen, Hans (2009), El defensor de la Constitución versus ¿Quién debe ser el defensor de la Constitución? (trad. M. Sánchez y R. Brie, Madrid, Tecnos). 
Silva Bascuñán, Alejandro (1993), "Misión del Tribunal Constitucional”, en Revista Chilena de Derecho 20/2-3, pp. 481-490.

Silva SÁnchez, Jesús-María (2007), “Hay jueces en Berlín! (y en Karlsruhe)”, en InDret 1, pp. 1-6.

Tocqueville, Alexis de (2005), La democracia en América Vol. 1 (trad. D. Sánchez, Madrid, Alianza).

Verdugo, Mario (2012), "Asamblea constituyente: ¿Invitación a un quiebre institucional?", en Diario constitucional (Informativo No 140), disponible en http://diarioconstitucional.cl/mostrararticulo.php?id=192.

Waldron, Jeremy (2005), Derecho y desacuerdos (trad J. L. Martí y Á. Quiroga, Madrid, M. Pons).

Waldron, Jeremy (2006), "The Core of the Case Against Judicial Review”, en The Yale Law Journal 115, pp. 1346-1406.

Waldron, Jeremy (2008), "Can There Be a Democratic Jurisprudence?”, en NELLCO Legal Scholarship Repository. New York University Public Law and Legal. Theory Working Papers, 57 pp.

WALDRON, Jeremy (2009a), "Judges as moral reasoners", en International Journal of Constitutional Law 7/1, pp. 2-24.

WALDRON, Jeremy (2009b), "Refining the question about judges' moral capacity", en International Journal of Constitutional Law 7/1, pp. 69-82.

Zagrebelsky, Gustavo (1995), El derecho dúctil. Ley, derechos, justicia (trad. M. Gascón, Madrid, Trotta).

Zapata, Patricio (2008), Justicia constitucional. Teoría y práctica en el derecho chileno y comparado (Stgo. de Chile, Jurídica de Chile).

Zurn, Christopher (2007), Deliberative Democracy and the Institutions of Judicial Review (N. York, Cambridge University Press).

\section{JURISPRUDENCIA CITADA}

Sentencia del Bundesverfassungsgericht (caso Lüth), disponible en Schwabe, Jürgen (2009), ed., Jurisprudencia del Tribunal Constitucional Federal alemán (trad. M. Anzola y E. Maus, México, Konrad Adenauer Stiftung), pp. 202-207.

Sentencia de la Supreme Court de EE.UU. (Caso roe v. Wade: 5 US (1 Cranch) 137), disponible en Beltrán, Miguel y González, Julio (2006), eds. y trads., 
Las sentencias básicas del Tribunal Supremo de los Estados Unidos de América (Madrid, CEPC, 2a. ed.), pp. 99-121.

Sentencia Rol No 591 del TC, fechada el $1^{\circ}$ de septiembre de 2006, por requerimiento de inconstitucionalidad de la Resolución Exenta No 584 (Ministerio de Salud), la cual aprueba Normas Nacionales sobre Regulación de la Fertilidad, disponible en http://www.tribunalconstitucional.cl/wp/ descargar_expediente.php?id=34129.

Sentencia rol 740 del TC, fechada el 18 de abril de 2008, por requerimiento de inconstitucionalidad deducido en contra de algunas disposiciones de las "Normas Nacionales sobre Regulación de la Fertilidad", aprobadas por el Decreto Supremo No 48, de 2007 (Ministerio de Salud), disponible en http:// www.tribunalconstitucional.cl/wp/descargar_expediente.php?id=34407.

Sentencia rol 1961-11 del TC, fechada el 10 de julio de 2012, por requerimiento de inaplicabilidad por inconstitucionalidad presentado por el Juzgado de Policía Local de María Pinto respecto de los artículos 207, letra b), de la Ley No 18.290 y 39 y 40 de la Ley No 18.287, en los autos Rol No 3482011 sobre acumulación de infracciones a la Ley de Tránsito seguidos ante el Juzgado de Policía Local de María Pinto en contra de Leonardo Tomás Montecinos Garcíavoto, disponible en http://www.tribunalconstitucional. $\mathrm{cl} / \mathrm{wp} /$ expedientes? rol=1961-11. 
